2014s-38

\title{
Endogenous savings rate with forward-looking households in a recursive dynamic CGE model: application to South Africa
}

André Lemelin

\section{Série Scientifique \\ Scientific Series}

Montréal

Juillet 2014

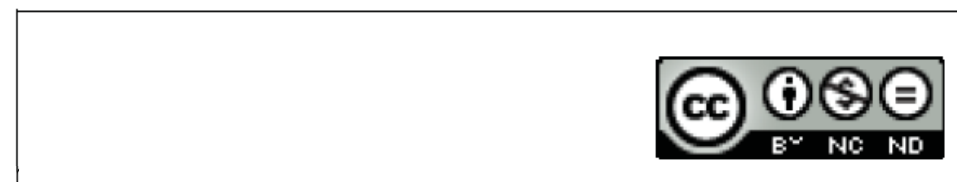

Sauf indication contraire, ce travail est sous licence

Except where otherwise noted, this work is licensed under

http://creativecommons.org/licenses/by-nc-nd/3.0/
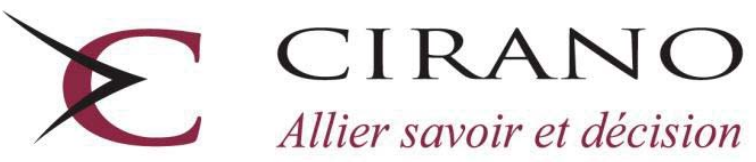

Allier savoir et décision

Centre interuniversitaire de recherche en analyse des organisations 


\section{CIRANO}

Le CIRANO est un organisme sans but lucratif constitué en vertu de la Loi des compagnies du Québec. Le financement de son infrastructure et de ses activités de recherche provient des cotisations de ses organisations-membres, d'une subvention d'infrastructure du Ministère de l'Enseignement supérieur, de la Recherche, de la Science et de la Technologie, de même que des subventions et mandats obtenus par ses équipes de recherche.

CIRANO is a private non-profit organization incorporated under the Québec Companies Act. Its infrastructure and research activities are funded through fees paid by member organizations, an infrastructure grant from the Ministère de l'Enseignement supérieur, de la Recherche, de la Science et de la Technologie, and grants and research mandates obtained by its research teams.

\section{Les partenaires du CIRANO}

\section{Partenaire majeur}

Ministère de l'Enseignement supérieur, de la Recherche, de la Science et de la Technologie

\section{Partenaires corporatifs}

Autorité des marchés financiers

Banque de développement du Canada

Banque du Canada

Banque Laurentienne du Canada

Banque Nationale du Canada

Bell Canada

BMO Groupe financier

Caisse de dépôt et placement du Québec

Fédération des caisses Desjardins du Québec

Financière Sun Life, Québec

Gaz Métro

Hydro-Québec

Industrie Canada

Intact

Investissements PSP

Ministère des Finances et de l'Économie

Power Corporation du Canada

Rio Tinto Alcan

Ville de Montréal

\section{Partenaires universitaires}

École Polytechnique de Montréal

École de technologie supérieure (ÉTS)

HEC Montréal

Institut national de la recherche scientifique (INRS)

McGill University

Université Concordia

Université de Montréal

Université de Sherbrooke

Université du Québec

Université du Québec à Montréal

Université Laval

Le CIRANO collabore avec de nombreux centres et chaires de recherche universitaires dont on peut consulter la liste sur son site web.

Les cahiers de la série scientifique (CS) visent à rendre accessibles des résultats de recherche effectuée au CIRANO afin de susciter échanges et commentaires. Ces cahiers sont écrits dans le style des publications scientifiques. Les idées et les opinions émises sont sous l'unique responsabilité des auteurs et ne représentent pas nécessairement les positions du CIRANO ou de ses partenaires.

This paper presents research carried out at CIRANO and aims at encouraging discussion and comment. The observations and viewpoints expressed are the sole responsibility of the authors. They do not necessarily represent positions of CIRANO or its partners.

ISSN 2292-0838 (en ligne)
Partenaire financier

Enseignement supérieur. Recherche, Science et Technologie Québec 


\title{
Endogenous savings rate with forward-looking households in a recursive dynamic CGE model: application to South Africa *
}

\author{
André Lemelin ${ }^{\dagger}$
}

\begin{abstract}
Résumé/abstract
Dans la plupart des modèles d'équilibre général calculable dynamiques séquentiels, le taux d'épargne est constant et exogène. Les modèles intertemporels, eux, sont résolus simultanément pour toutes les périodes et les ag ents pratiquent l'optimisation intertemporelle. Mais la cohérence théorique de l'optimisation intertemporelle n'est atteinte qu'au prix de modèles moins détaillés, à cause de limites sur le volume des calculs. C'est pourquoi, quand le détail des résultats est important, on peut préférer utiliser un modèle dynamique séquentiel. Cet article présente un modèle d'équilibre général calculable dynamique séquentiel dans lequel les ménages déterminent leur taux d'épargne par l'optimisation intertemporelle, en résolvant une forme simplifiée de leur problème intertemporel. C'est ce que nous appelons des « anticipations rationnelles tronquées » (TRE). Dans ce cadre, les ménages ont des anticipations rationnelles pour la pé riode courante et la sui vante. Le m odèle est donc $r$ ésolu simultanément pour deux périodes à la fois, la courante $\tau$ et la suivante. Les anticipations rationnelles des ménages pour la période $\tau+1$ sont données par la solution du modèle. Pour les périodes subséquentes, les anticipations sont formées par extrapolation à partir des valeurs de $\tau$ et $\tau+1$, en supposant un taux de changement constant. L'approche TRE est implantée dans une version modifiée du modèle PEP-1-t de Decaluwé et al. (2013), au moyen d'une matrice de comptabilité sociale (MCS) de l'Afrique du Sud pour 2005 due à Davies and Thurlow (2011). Différentes simulations sont menées, avec deux variantes de la MCS, l'originale et une version modifiée avec un taux élevé d'épargne des ménages. Les résultats sont comparés avec ceux d'un modèle avec anticipations statiques et optimisation intertemporelle, et avec ceux d'un modèle à taux d'épargne fixe. La principale différence observée est que dans les deux premiers modèles, le taux d'épargne des ménages n'est pas constant, même dans le scénario de référence. De plus, il réagit aux variations du taux de rendement des actifs. Par contre, une réduction exogène du stock de richesse des ménage a très peu d'impact.
\end{abstract}

Mots clés : Modèles d'équilibre général calculable, modèles dynamiques séquentiels, optimisation intertemporelle, épargne des ménages .

\footnotetext{
*Text of a presentation made at the 54th annual meeting of the Société canadienne de science économique, Ottawa, 14-16 mai 2014.

${ }^{\dagger}$ Centre INRS-UCS, Université du Québec, Montréal andre_lemelin@ucs.inrs.ca
} 
In the vast majority of recursive dynamic CGE models, the savings rate is constant and exogenous. Intertemporal CGE models, by contrast, are solved simultaneously for all periods, and agents optimize intertemporally. But the theoretical consistency of intertemporal optimization is achieved only at the cost of more aggregated, less detailed models, due to computational limitations. In some applications, therefore, recursive dynamics should be preferred to intertemporal dynamics for practical reasons of computability. This paper presents a recursive dynamic CGE model in which households determine their savings rate from intertemporal optimization, by solving a simplified form of their intertemporal problem. This approach we call « truncated rational expectations » (TRE). In the TRE framework, households have rational expectations for the current period and the following one. Accordingly, the model is solved simultaneously for two periods at a time, the current period $\tau$ and the following one. Household (rational) expectations for period $\tau+1$ are given by the model solution. For subsequent periods, household expectations are formed by extrapolating from $\tau$ and $\tau+1$ solution values, assuming a constant rate of change. The TRE framework is implemented in a modified version of the Decaluwé et al. (2013) PEP-1-t model, and applied to South Africa, using a 2005 SAM by Davies and Thurlow (2011). Several simulations are run, with two variants of the 2005 SAM, the original one and a modified one with a high initial household savings rate. The results are compared with those of a static expectations model with intertemporal optimization, and of a fixed-savings rate model. The main difference is that in the first two models, the household savings rate is not constant, even in the BAU scenario. It is also responsive to changes in the rate of return on assets. On the other hand, an exogenous reduction in household wealth has very little effect.

Key words: Computable general equilibrium models, recursive dynamic models, intertemporal optimization, household savings

Codes JEL : C68, D1, D58, D91 


\section{Contents}

Résumé $\quad 3$

Classification JEL et mots-clés 3

Summary

JEL classification and key words $\quad 4$

$\begin{array}{ll}\text { Contents } & 5\end{array}$

$\begin{array}{ll}\text { Introduction } & 7\end{array}$

1. Theoretical (re)formulation of the household intertemporal problem 9

Terminology and notation $\quad 9$

$\begin{array}{ll}1.1 \text { Intertemporal problem with non-depreciating asset } & 10\end{array}$

1.2 Intertemporal problem with depreciating asset and classic accumulation rule 11

1.3 Tobin's Q and the discount rate 13

1.4 Solution of the theoretical model 15

2. Model 17

2.1 Household income and wealth 17

2.1.1 Household income from capital and wealth 17

2.1.2 Household disposable income from capital and other 21

2.2 Rates of return and the interest rate $\quad 22$

2.3 Household savings $\quad 24$

2.4 Household wealth accumulation 25

2.5 Household dynamic budget constraint 26

2.6 Truncated rational expectations $\quad 27$

2.7 Model solution 28

2.8 Model summary 31

3. Application to South Africa, 2005

3.1 SAM 36

$\begin{array}{ll}\text { 3.2 Parametrization } & 37\end{array}$ 
$\begin{array}{ll}3.3 \text { Closure } & 38\end{array}$

$\begin{array}{ll}3.4 \text { Simulations } & 38\end{array}$

$\begin{array}{ll}3.5 \text { Results } & 38\end{array}$

3.5.1 Simulation 1: permanent 50\% drop in the international price of minerals 38

3.5.2 Simulation 2: confiscation of $20 \%$ of household wealth 47

3.5.3 Simulation 3: 2\%/10\% surtax on household capital income 51

3.5.4 Summary of simulation results 53

3.6 Alternative models 53

3.6.1 Static expectations 53

3.6.2 Fixed savings rate $\quad 55$

Conclusion: What remains to be done 56

$\begin{array}{ll}\text { References } & 57\end{array}$

$\begin{array}{ll}\text { Appendix : Aggregation } & 59\end{array}$

Appendix : The endogenous investment scale variable as a rationing device 61 


\section{Introduction}

Dynamic computable general equilibrium (CGE) models may be classified into recursive and intertemporal. Recursive dynamic CGE models are solved as a succession of st atic models, one period at a time, each period inheriting som e exogenous variables (most notably the stock of capit al) from the previous one ${ }^{1}$. In such $\mathrm{m}$ odels, households and other ec onomic agents optimize their choices without knowing the future, and, most of the time, ignoring it (in recursive dynam ic CGE models, expectations, even adaptive expectations, generally play no part in agents' behavior). Intertem poral CGE models, by contrast, are solved sim ultaneously for all periods, and agents optim ize intertemporally. Intertemporal models may be deterministic or stochastic. In determ inistic intertemporal models, agents are usually gifted with perfect foresight. In dynamic stochastic general equilibrium (DSGE) models, agents are faced with uncertainty, and they optimize the mathematical expectation of future outcomes ${ }^{2}$.

We concur with Babiker et al. (2009) that neither the recursive nor the intertemporal approach dominates the other. Comparing two versions of the MIT EPPA m odel, one recursive, the other intertem poral, they point out that « the forward-looking $\mathrm{m}$ odel also had to be sim plified in some regards to $\mathrm{m}$ ake it computationally feasible », and draw the following conclusion:

« Economists typically consider forward-looking models a significant advance over the recursive structure because in reality agents expectations about the future affect current behavior.

However, for policy purposes the tradeo ff of less structural detail and the assu mption of perfect foresight over all time (as opposed to uncertain expectations of what might happen in the future) leaves open the question of which for mulation gives more realistic answers. Some problems simply demand the forward-looking structure to get at basic issues, while for others the recursive structure may be more realistic. We thus see these two versions as complementary. » (p.1342)

So the theoretical consistency of inte rtemporal optimization is achieved o nly at the cost of $\mathrm{m}$ ore aggregated, less detailed $\mathrm{m}$ odels, due to com putational limitations. In some applications, therefore, recursive dynamics should be preferred to intertemporal dynamics for practical reasons of computability.

Moreover, the rational ex pectations paradigm which underlies intertem poral models has been criticized on the grounds that « DSGE models (and more generally of macroecono mic models based on rational expectations) [...] assume extraordinary cognitive capabilities of individual agents » (de Grauwe, 2010;

1 The reader must be warn ed that usage of the word « recursive » is not full y stabilized, witness the Wikip edia article on « Recursive economics », which refers to what we call here « intertemporal».

2 Uncertainty in these models often takes the for $\mathrm{m}$ of «technological shocks» on multi-factor productivity, with known probability distribution. Some DSGE models are solved each period for all time up to the horizon, on the basis of past and current outcomes. 
also see de Grauwe, 2012). The same author then goes on to argue that « we need models that take into account the limited cognitive abilities of agents ».

This argument, together with the practical limitations of intertemporal models, has prompted us to follow H.A. Simon $(1978,1982)$, and make the hy pothesis that, un der the bounded rationality principle, households solve a si mplified form of their intertem poral problem. This approach, which we call « boundedly rational expectations », is what we develop in this paper. ${ }^{3}$

More specifically, we apply the bounded rationality principle to household decisions regarding t he allocation of their income between savings and cons umption. In addition to the $\mathrm{m}$ otivations expressed above, an objective of this project is to devel op an operational CGE modelling approach to endogenize the household savings rate in a recursive dy namic model. Specifically, we want the household savings rate to be responsive to changes in the rate of return on assets. Furtherm ore, it should reflect the adjustment behavior of households facing economic shocks that change the value of their capital endowment. And in the true spirit of CGE m odeling, we want our model to rest upon a sound theoretical basis, which is why a formulation with forward-looking households is so attractive.

In the vast majority of CGE models, the savings rate is constant and exogenous. In som e models, such as the IFPRI standard $\mathrm{m}$ odel (Löfgren et al., 2002), the househol $\mathrm{d}$ savings rate $\mathrm{m}$ ay be endogenousl $\mathrm{y}$ determined so as to acco mmodate some exogenous amount of investment expenditures (SI-1 closure). In other models, savings are treated as a proxy for $\mathrm{f}$ uture consumption, and are jointly determined with household current consumption expenditure ${ }^{4}$.

An earlier paper (Lemelin 2012) put forth a theoretical model of the representative household that meets these objectives. In the $\mathrm{m}$ odel, household consum ption expenditures and savings are determined under intertemporal optimization. Two variants of the model were examined. In the first, households have static expectations: they expect consumer prices, their non-investment income and the rate of return on savings to remain at their current values indefinitely ${ }^{5}$. In the second variant, households make their decisions on the basis of boundedly-rational, or truncated rational expectations: households are assumed to have nearperfect foresight one period ahead and to extrapolate changes between the current and the next period into the future to form their expectations.

3 Another approach to m itigate the stringency of the rational expectations hypothesis, applied in several DSGE models, is to consider two classes of households, one of which has rational expectations and acts accordingly, while the other (often called « constrained ») follows a more mechanical behavior.

4 An early example is the extended linear expenditure system (ELES) (Lluch, 1973; Howe, 1775). Also, see Part 2 in Lemelin and Decaluwé (2007). Similar approaches are found in the GTAP model and the MIT EPPA model.

5 Static expectations are also called « myopic expectations »: Evans and Honkapohja (2001). 
Certainly, the proposed approach, especially truncated rational expectations, poses i mplementation challenges. It was first applied, with success, in a «toy model» in which reduced size mini mized the computational burden so that the $\mathrm{m}$ ain programming issues could be resolve $\mathrm{d} .{ }^{6}$ But it remained to be shown that the approach is applicable to a « real life » situation. This is what this paper demonstrates, by applying the truncated rational expectations model to South Africa, 2005.

The first part of the paper briefly reviews the under lying theory. The second part describes how the theoretical model is im plemented in the PEP-1-t standard recursive dy namic CGE model (Decaluwé et al., 2013). The third part presents an application to South Africa, 2005, and di scusses some preliminary results. A brief conclusion assesses wh at remains to be done for the $\mathrm{m}$ odel to become fully operational and applicable in a general context.

\section{Theoretical (re)formulation of the household intertemporal problem}

\section{Terminology and notation}

In this essay, the expression « current assets » designates assets owned by the household at the beginning of the current period. The expression « terminal wealth » or « residual wealth » means assets to be left at the end of the final period of the household' s planning time-span, occasionally called « target assets ». In the models examined, there are two sources of inco me, investment income and non-investment income; when the word « income» is not qualified, it mean s non-investment income. The expression « dynamic budget constraint» designates the household's single-period constraint; the intertem poral budget constraint, also called the lifetime budget constraint, covers the entire household planning time-span.

Theoretical equations are numbered [ttt001] to [ttt047]. PEP model equations are designated by an « $\mathrm{M} »$ followed by a three-digit number. Other equations are numbered [iii 001] to [iii 023].

6 Results were presented at the $53^{\mathrm{e}}$ annual meeting of the Soci été canadienne de science écono mique, Québec, May 15-17, 2013 under the title "L'épargne des ménages dans un MEGC d ynamique séquentiel avec optimisation intertemporelle et anticipations rationnelles tronquées », and later at the $47^{\text {th }}$ annual meeting of the Canadian Economics Association, Montréal, May 30-June 2, 2013: « Household savings in a recursive dynamic CGE model with intertemporal optimization and truncated rational expectations ». 


\subsection{Intertemporal problem with non-depreciating asset}

Start with the household intertemporal problem in its standard theoretical form

$$
\max _{\left\{c_{t}\right\}_{t=\tau}^{T}} U_{\tau}=\sum_{t=\tau}^{T} \beta^{t-\tau} u\left(c_{t}\right)
$$

subject to the dynamic budget constraint

$$
a_{t+1}=\left(1+r_{t}\right)\left(a_{t}+y_{t}-p_{t} c_{t}\right), t=\tau, \ldots, T
$$

and the transversality (no Ponzi game) condition

$$
a_{T+1}=\overline{a_{T+1}}
$$

where

$c_{t}$ is the volume of consumption in period $t$

$\beta$ is the subjective discount factor: $\beta=1 /(1+\psi)$

$\psi$ is the psychological discount rate, or time-preference, or rate of impatience

$u\left(c_{t}\right)$ is the single-period utility function

$a_{t}$ is the nominal value of the household's assets (or wealth, or capital endowment) at the beginning of period $t$

$p_{t}$ is the price index of consumption in period $t$

$y_{t}$ is the household's nominal non-investment income in period $t$

$r_{t}$ is the nominal rate of interest in period $t$

and where the single-period utility function is specified as the $\mathrm{CRRA}^{7}$ utility function

$$
u\left(c_{t}\right)=\frac{c_{t}^{1-\varsigma}}{1-\varsigma}
$$

with intertemporal elasticity of substitution(IES) $\sigma=1 / \varsigma$. Dynamic budget constraint [ttt002] is equivalent to the intertemporal budget constraint

$$
p_{\tau} c_{\tau}+\sum_{t=\tau+1}^{T}\left[\prod_{\theta=\tau}^{t-1}\left(\frac{1}{1+r_{\theta}}\right)\right] p_{t} c_{t}+\prod_{\theta=\tau}^{T}\left(\frac{1}{1+r_{\theta}}\right) a_{T+1}=a_{\tau}+y_{\tau}+\sum_{t=\tau+1}^{T}\left[\prod_{\theta=\tau}^{t-1}\left(\frac{1}{1+r_{\theta}}\right)\right] y_{t}
$$

7 Constant Relative Risk Aversion. Actually, risk is absent from this model, so « risk aversion » merely characterizes the shape of the utility function. 
where $\tau$ is the current pe riod, and $T$ is the final $\mathrm{pl}$ anning period currently considered by households. Maximizing [ttt001] subject to [ $\mathrm{ttt} 004$ ] yields the first-order conditi ons from which is derived the Eule $\mathrm{r}$ equation

$$
\left(1+r_{\tau}\right) \beta u^{\prime}\left(c_{\theta+1}\right)=u^{\prime}\left(c_{\theta}\right)
$$

\subsection{Intertemporal problem with depreciating asset and classic accumulation rule}

The dynamic budget constraint in [ttt002], however, assumes that household assets do not depreciate, and that current savings generate interest income. To ta ke explicit account of depreciation and of the delay in income generation from assets, let us reform ulate the problem in term s of capital ${ }^{8}$ within a sim ple economywide model. Let the (classic) capital accumulation rule be

$$
k_{t+1}=(1-\delta) k_{t}+I_{t} / p_{k, t}
$$

where

$k_{t}$ is the stock of capital in period $t$

$\delta$ is the rate of depreciation

$I_{t}$ is the amount of investment expenditures in period $t$

$p_{k, t}$ is the price of the investment good in period $t$

Under the classic capital accu mulation rule, new capital created by current invest ment becomes productive only in the following period. This specification is at variance with the assumption, made in the theoretical model of section 1.1, that current savings generate interest income.

Next, let $z_{t}$ be income, and the budget constraint is

$$
z_{t}=p_{c, t} c_{t}+I_{t}
$$

where

$c_{t}$ is consumption in period $t$

$p_{c, t}$ is the price of the consumption good in period $t$

So we have

$$
k_{t+1}=(1-\delta) k_{t}+\frac{z_{t}-p_{c, t} c_{t}}{p_{k, t}}
$$


For the sake of this theoretical model, we assume perfect factor m obility and constant-ret urns-to-scale production functions ${ }^{9}$. Perfect mobility implies that factor prices are equal between the consu mer goods producing industry and the investment goods producing industry. Constant returns to scale imply

$$
\begin{aligned}
& c_{t}=\frac{\partial c_{t}}{\partial k_{c, t}} k_{c, t}+\frac{\partial c_{t}}{\partial l_{c, t}} l_{c, t}=\frac{w_{k, t} k_{c, t}+w_{l, t} l_{c, t}}{p_{c, t}} \\
& \frac{I_{t}}{p_{k, t}}=\frac{\partial\left(I_{t} / p_{k, t}\right)}{\partial k_{k, t}} k_{k, t}+\frac{\partial\left(I_{t} / p_{k, t}\right)}{\partial l_{k, t}} l_{k, t}=\frac{w_{k, t} k_{k, t}+w_{l, t} l_{k, t}}{p_{k, t}}
\end{aligned}
$$

where

$k_{i, t}$ is the quantity of capital used in industry $i$ in period $t$

$l_{i, t}$ is the quantity of labor used in industry $i$ in period $t$

$w_{k, t}$ is the rental rate of capital in period $t$

$w_{l, t}$ is the wage rate in period $t$

Factor market equilibrium requires

$$
\begin{aligned}
& l_{t}=l_{c, t}+l_{k, t} \\
& k_{t}=k_{c, t}+k_{k, t}
\end{aligned}
$$

Let

$$
\begin{aligned}
& y_{t}=w_{l, t} l_{t} \\
& w_{k, t}=\rho_{t} p_{k, t}
\end{aligned}
$$

Then, substituting [ttt009], [tt010], [ttt011], [ttt012], [ttt013], and [ttt014] into [ttt007]

$$
z_{t}=p_{c, t} c_{t}+I_{t}=\rho_{t} p_{k, t} k_{t}+y_{t}
$$

Next, substitute [ttt015] into [ttt008]:

$$
\begin{aligned}
& k_{t+1}=(1-\delta) k_{t}+\frac{\rho_{t} p_{k, t} k_{t}+y_{t}-p_{c, t} c_{t}}{p_{k, t}} \\
& p_{k, t} k_{t+1}=(1-\delta) p_{k, t} k_{t}+\rho_{t} p_{k, t} k_{t}+y_{t}-p_{c, t} c_{t} \\
& p_{k, t} k_{t+1}=\left(1+\rho_{t}-\delta\right) p_{k, t} k_{t}+y_{t}-p_{c, t} c_{t}
\end{aligned}
$$

\footnotetext{
9 In the applied model presented later, we no longer assume perfect factor mobility.
} 
Compared with equation [ttt002],

$$
a_{t+1}=\left(1+r_{t}\right)\left(a_{t}+y_{t}-p_{t} c_{t}\right), t=\tau, \ldots, T
$$

there are two differences. The first i s that the rate of return $r_{t}$ is replaced by $\rho_{t}-\delta$ to take account of depreciation. The second difference is that the surplus of labor-inc ome over consumption does not yield any return under an accu mulation rule according to which new capital cr eated by investment beco mes operational with a one-period delay . However, contrary to first i mpression, $\rho_{t}-\delta$ is no $t$ the correct discount rate to compute present values in the intertemporal problem, as we shall see below.

Finally, we define current savings from the single-period budget constraint [ttt018] as

$$
s_{t}=p_{k, t}\left(k_{t+1}-k_{t}\right)=\left(\rho_{t}-\delta\right) p_{k, t} k_{t}+y_{t}-p_{c, t} c_{t}
$$

In view of capital accu mulation rule [ $\mathrm{ttt} 006]$, it is clear that eq uation [ttt019] defines net savings. To verify, rewrite [ttt006] as

$$
\begin{aligned}
& p_{k, t} k_{t+1}=(1-\delta) p_{k, t} k_{t}+I_{t} \\
& p_{k, t}\left(k_{t+1}-k_{t}\right)=I_{t}-\delta p_{k, t} k_{t}
\end{aligned}
$$

Savings as defined in [ttt019] are indeed net savings, equal to net investments.

\subsection{Tobin's $Q$ and the discount rate}

Suppose a capitalist purchases one unit of capital at the beginning of period $t$ for a price of $p_{k, t}$. Since there is no vintage distinction within the stock of capital, acquiring one unit of existing capital or making an investment to create one unit of new capital must be equivalent. Therefore, capital acquired in period $t$ yields income only in $t+1$, whether it is new or pre-existing capital ${ }^{10}$. So the scenario goes as follows.

A unit of capital acquired in period $t$ for a price of $p_{k, t}$ will generate no income in period $t$, and an income of $w_{k, t+1}$ in period $t+1$; the $(1-\delta)$ fraction of capital remaining after depreciation may be resold in the same period $t+1$ for an am ount of $(1-\delta) p_{k, t+1}$ to someone who will receive $\mathrm{n}$ o income in $t+1$, and $(1-\delta) w_{k, t+2}$ in $t+2$, etc. The present value of the capitalist's income must be equal to the cost

10 Pre-existing capital does gen erate income in the current period, but that income goes to the ag ent who owned the capi tal at the beginning of the current period. 
of the investment:

$$
p_{k, t}=\frac{w_{k, t+1}}{1+r_{t}}+(1-\delta) \frac{p_{k, t+1}}{1+r_{t}}
$$

where $r_{t}$ is the forward-looking discount rate. We have

$$
\begin{aligned}
& \left(1+r_{t}\right) p_{k, t}=w_{k, t+1}+(1-\delta) p_{k, t+1} \\
& \left(1+r_{t}\right) \frac{p_{k, t}}{p_{k, t+1}}=\frac{w_{k, t+1}}{p_{k, t+1}}+(1-\delta)
\end{aligned}
$$

The ratio of the rental rate of capital on its price (replacement cost),

$$
\rho_{t}=\frac{w_{k, t}}{p_{k, t}}
$$

is the (gross) rate of return on capital. Also, define the growth fa ctor of the pr ice of investment goods $g_{p k, t}$, and the corresponding rate of inflation $\pi_{p k, t}$ :

$$
1+\pi_{p k, t}=g_{p k, t}=\left(\frac{p_{k, t+1}}{p_{k, t}}\right)
$$

Then

$$
\begin{aligned}
& \frac{\left(1+r_{t}\right)}{g_{p k, t}}=\rho_{t+1}+(1-\delta) \\
& \left(1+r_{t}\right)=\left(1+\rho_{t+1}-\delta\right) g_{p k, t}=\left(1+\rho_{t+1}-\delta\right)\left(1+\pi_{p k, t}\right)
\end{aligned}
$$

Equation [ttt028] defines the forward-looking discount rate for which Tobin's Q is equal to 1 under the classic accumulation rule. This is the correct discount rate to use in co mputing present values in th $\mathrm{e}$ household's intertemporal budget constraint. Now, rewrite [ttt028] as

$$
\rho_{t+1}=\left(\frac{1+r_{t}}{1+\pi_{p k, t}}\right)-(1-\delta)=\left(\frac{1+r_{t}}{g_{p k, t}}\right)-(1-\delta)
$$

Define the real rate of interest as

$$
\widetilde{r}_{t}=\left(\frac{1+r_{t}}{1+\pi_{p k, t}}\right)-1=\left(\frac{1+r_{t}}{g_{p k, t}}\right)-1
$$


Equation [ttt029] becomes

$$
\rho_{t+1}=\left(1+\widetilde{r}_{t}\right)-(1-\delta)=\widetilde{r}_{t}+\delta
$$

This is the user cost of capital: but under the classic accu mulation rule, with a one-period lag before investment becomes productive capital, the user cost of capital expected in period $t+1, \rho_{t+1}$, depends on the real forward-looking rate of interest in period $t$.

In the particular case of static expectations, $\pi_{p k, t}=0$ and

$$
r_{t}=\rho_{t}-\delta
$$

\subsection{Solution of the theoretical model}

The household's intertemporal optimization problem is

$$
\max _{\left\{c_{t}\right\}_{t=\tau}^{T}} U_{\tau}=\sum_{t=\tau}^{T} \beta^{t-\tau} u\left(c_{t}\right)
$$

subject to the dynamic budget constraint

$$
p_{k, t} k_{t+1}=\left(1+\rho_{t}-\delta\right) p_{k, t} k_{t}+y_{t}-p_{c, t} c_{t}, t=\tau, \ldots, T
$$

and the transversality (no Ponzi game) condition

$$
k_{T+1}=\overline{k_{T+1}}
$$

We shall detail below how, under truncated rational expectations (TRE), the growth rates

$$
\begin{aligned}
& g_{y, \tau}=\frac{y_{\tau+1}}{y_{\tau}} \\
& g_{p c, \tau}=\frac{p_{c, \tau+1}}{p_{c, \tau}} \\
& g_{p k, \tau}=\frac{p_{k, \tau+1}}{p_{k, \tau}} \\
& g_{\rho, \tau}=\frac{\rho_{\tau+1}}{\rho_{\tau}}=\frac{w_{k, \tau+1} / w_{k, \tau}}{p_{k, \tau+1} / p_{k, \tau}}=\frac{g_{w k, \tau}}{g_{p k, \tau}}
\end{aligned}
$$

are expected to be constant. Under thos e conditions, it has been demonstrated in Lemelin (2013) that the first-order conditions of that problem yield the following Euler equation for any future period $\theta \geq \tau$ : 


$$
\left(1+g_{\rho, \tau}^{\theta+1-\tau} \rho_{\tau}-\delta\right) \frac{g_{p k, \tau}}{g_{p c, \tau}} \beta u^{\prime}\left(c_{\theta+1}\right)=u^{\prime}\left(c_{\theta}\right)
$$

The intertemporal budget constraint is obtained by su mming the present value of the dynamic (singleperiod) budget constraint for all pe riods, beginning with current period $\tau$, and ending with planning horizon $T$. Applying this to equation [ttt018] yields

$$
\sum_{t=\tau}^{T} D_{t} g_{p c, \tau}^{t-\tau} p_{c, \tau} c_{t}=p_{k, \tau} k_{\tau}-D_{T} g_{p k, \tau}^{T-\tau} p_{k, \tau} \overline{k_{T+1}}+\left(\rho_{\tau}-\delta\right) p_{k, \tau} k_{\tau}+\sum_{t=\tau}^{T} D_{t} g_{y, \tau}^{t-\tau} y_{\tau}
$$

where

$$
D_{t}=\left(\frac{1}{g_{p k, \tau}}\right)^{t-\tau} \prod_{\theta=1}^{t-\tau}\left(\frac{1}{\left(1+g_{\rho, \tau}^{\theta} \rho_{\tau}-\delta\right)}\right)
$$

with the convention that

$$
D_{\tau}=1
$$

$D_{t}$ is the discount factor, taking into account the expected evolution of the interest rate.

The left-hand side of [ $\mathrm{ttt} 038$ ] is the present value of all consu mption expenditures to the horizon. This is constrained to be less than the sum of: (1) the surplus of current assets over the present value of term inal assets, (2) current income fro $\mathrm{m}$ capital, and (3) the present value of non-investm ent income to the horizon. In equilibrium, constraint [ttt038] holds with equality: if the present value of consum ption were less than the right-hand si de of equation [ $\mathrm{ttt} 038$ ], then the household could i mprove its welfare without violating its budget constraint by raising consumption.

The next step in solving the intertem poral optimization problem is to substitute a specific form of the utility function, here the CRRA utility function

$$
u\left(c_{t}\right)=\frac{c_{t}^{1-\varsigma}}{1-\varsigma}
$$

into Euler equation [ttt037], and, by recursion, obtain

$$
c_{t}=D_{t}^{-\sigma}\left(g_{p c, \tau}^{-1} \beta\right)^{(t-\tau) \sigma} c_{\tau}
$$

The solution is obtained by substituting [ttt041] into the intertemporal budget constraint [[ $\mathrm{ttt} 038]$. After some manipulation, the model solution is given by 


$$
p_{c, \tau} c_{\tau}=\frac{1}{F_{\tau}}\left[p_{k, \tau} k_{\tau}-D_{T} g_{p k, \tau}^{T-\tau} p_{k, \tau} \overline{k_{T+1}}+\left(\rho_{\tau}-\delta\right) p_{k, \tau} k_{\tau}+G_{\tau} y_{\tau}\right]
$$

where

$$
\begin{aligned}
& F_{\tau}=\sum_{t=\tau}^{T} D_{t}^{1-\sigma} g_{p c, \tau}^{(t-\tau)(1-\sigma)} \beta^{(t-\tau) \sigma} \\
& G_{\tau}=\sum_{t=\tau}^{T} D_{t} g_{y, \tau}^{t-\tau}
\end{aligned}
$$

\section{Model}

In this section, the theoretical $\mathrm{m}$ odel of section 1 is reformulated to be integrated to an applied CGE model. We start with the PEP-1-t standard recursive dynam ic CGE model (Decaluwé et al., 2013), which we modify to make the household savings $r$ ate endogenous, based on intertem poral optimization with truncated rational expectations.

In what follows, therefore, we proceed to translate the theoretical model developed in the first section into the PEP-1-t notation. More specifically, we seek to identify the terms of the dynamic budget constraint

$$
p_{k, t} k_{t+1}=\left(1+\rho_{t}-\delta\right) p_{k, t} k_{t}+y_{t}-p_{c, t} c_{t}
$$

or, equivalently, of the net savings equation derived from [ttt018]

$$
s_{t}=p_{k, t}\left(k_{t+1}-k_{t}\right)=\left(\rho_{t}-\delta\right) p_{k, t} k_{t}+y_{t}-p_{c, t} c_{t}
$$

\subsection{Household income and wealth}

The reader is refered to Decaluwé et al. (2013) for a detailed description of the PEP-1-t standard model. Here, we sh all describe the changes that are brought to $t$ he model to im plement truncated rational expectations (PEP-1-t-TRE; henceforth PEP-TRE for short).

\subsubsection{Household income from capital and wealth}

Model equations M 012, M 018, M 023 and M 044 describe the distribution of incom e from capital. In PEP-TRE, the share parameters are no longer fixed as calibrated, but they evolve through time as agents save and accumulate capital ownership; so the share para meters are now variables, with a time subscript: $\lambda_{h, k, t}^{R K}$ 


$\left.\begin{array}{l|l|}\hline \mathrm{M} & Y H K_{h, t}=\sum_{k} \lambda_{h, k, t}^{R K}\left(\sum_{j} R_{k, j, t} K D_{k, j, t}\right) \\ \hline \mathrm{M} & Y F K_{f, t}=\sum_{k} \lambda_{f, k, t}^{R K}\left(\sum_{j} R_{k, j, t} K D_{k, j, t}\right)\end{array}\right]$

where

$e_{t}: \quad$ Exchange rate ${ }^{11}:$ price of foreign currency in terms of local currency

$I M_{i, t}: \quad$ Quantity of product $i$ imported

$K D_{k, j, t}$ : Demand for type $k$ capital by industry $j$

$L D_{l, j, t}: \quad$ Demand for type $l$ labor by industry $j$

$P W M_{i, t}$ : World price of imported product $i$ (expressed in foreign currency)

$R_{k, j, t}: \quad$ Rental rate of type $k$ capital in industry $j$

$T R_{a g, a g j, t}:$ Transfers from agent $a g j$ to agent $a g$

$W_{l, t}: \quad$ Wage rate of type $l$ labor

$Y_{f, t}:$ Capital income of type $f$ businesses

$Y G K_{t}: \quad$ Government capital income

$Y_{h, t}:$ Capital income of type $h$ households

$Y R O W_{t}:$ Rest-of-the-world income

11 The default choice of numeraire in PEP-1-t is the exchange rate $e$. This is implemented by fixing the value of $e$ as exogenous. But the choice of numeraire in a CGE model is arbitrary (although the interpretation of results can be more or less easy, depending on which numeraire is selected). 
As in the theoretical model, the only asset in PEP-TRE is productive capital. It is assu med that capital income shares are equal to capital ownership shares. Consequently, household wealth is defined as

$$
\begin{aligned}
& \mathrm{M} \\
& 116 .
\end{aligned} W_{h, t}=P K_{t}^{P R I} \sum_{k, j}\left(\lambda_{h, k, t}^{R K} K D_{k, j, t}\right)
$$

where

$K W_{h, t} \quad$ Stock of capital owned by household $h$, valued at replacement cost

$$
P K_{t}^{P R I}: \text { Price of new private capital }
$$

The dynamics of ownership shares takes into account depreciation and investment. Investment is financed from pooled savings (equation M 089):

$$
\text { M } I T_{t}=\sum_{h} S H_{h, t}+\sum_{f} S F_{f, t}+S G_{t}+S R O W_{t}
$$

where

$$
\begin{array}{ll}
I T_{t}: & \text { Total investment expenditures } \\
S F_{f, t}: & \text { Savings of type } f \text { businesses } \\
S G_{t}: & \text { Government savings } \\
S H_{h, t}: & \text { Savings of type } h \text { households } \\
S R O W_{t}: & \text { Rest-of-the-world savings }
\end{array}
$$

So it is reasonable to assume that ownership of the new capital cr eated from investment is distributed in proportion to each agent's savings. The accumulation equation is

$$
\text { 103. } K D_{k, j, t+1}=K D_{k, j, t}\left(1-\delta_{k, j}\right)+I N D_{k, j, t}
$$

where

$$
\begin{aligned}
& \delta_{k, j}: \quad \text { Depreciation rate of capital } k \text { used in industry } j \\
& I N D_{k, j, t}: \text { Volume of new type } k \text { capital investment to sector } j
\end{aligned}
$$

The dynamics of capital ownership shares follow 


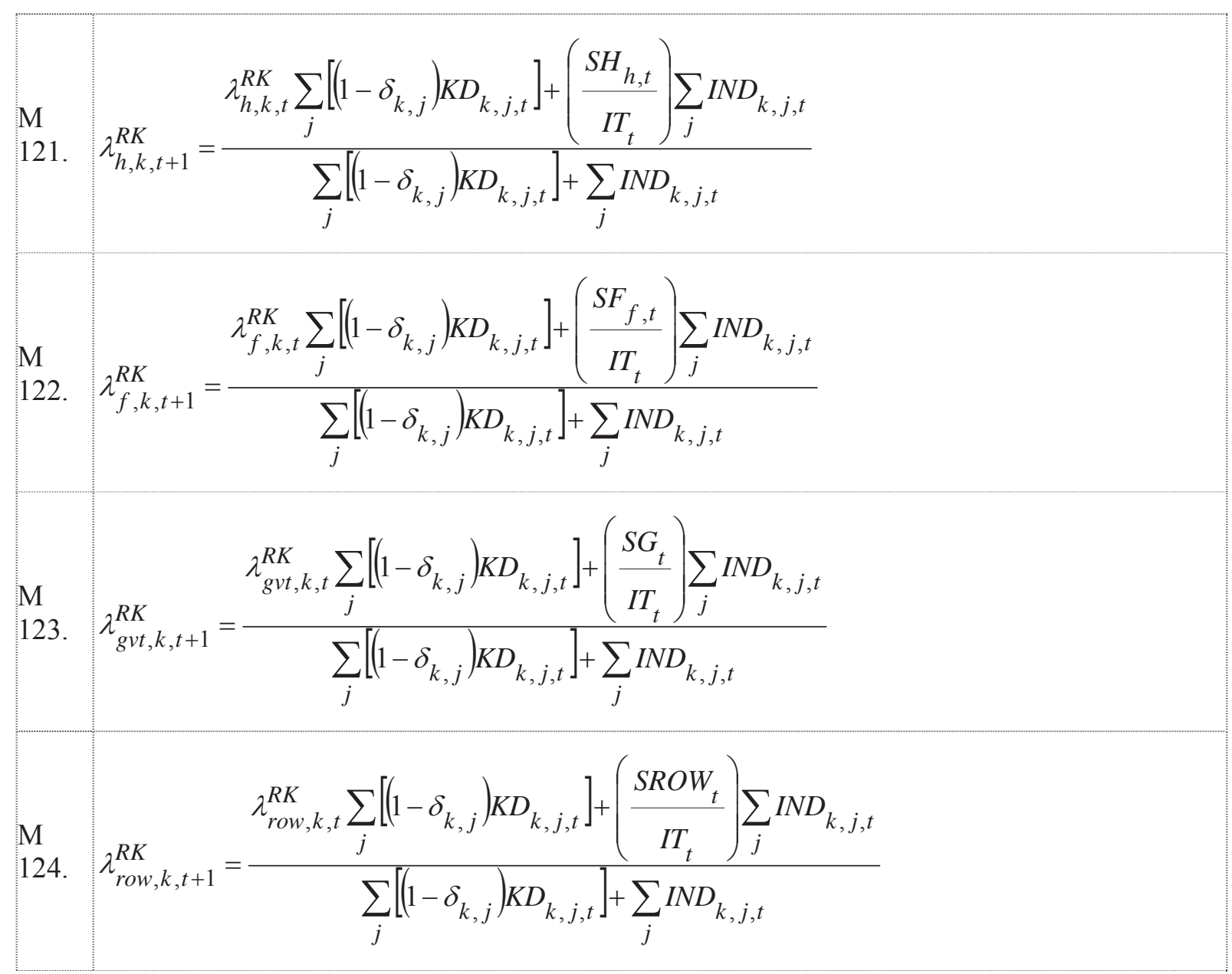

These equations hold insofar as

$$
\text { iii } I T_{t}=P K_{t}^{P R I} \sum_{k, j} I N D_{k, j, t}
$$

In view of equation M 090,

$$
\text { M90. } I T_{t}^{P R I}=I T_{t}-I T_{t}^{P U B}-\sum_{i} P C_{i, t} V S T K_{i, t}
$$

where

$I T_{t}^{P R I}: \quad$ Total private investment expenditures

$I T_{t}^{P U B}: \quad$ Total public investment expenditures

$P C_{i, t}: \quad$ Purchaser price of composite comodity $i$ (including all taxes and margins)

$V S T K_{i, t}:$ Inventory change of commodity $i$ 
this requires that stock variations $\operatorname{VSTK}_{i, t}$ be zero, a condition which is met in our application to South Africa.

\subsubsection{Household disposable income from capital and other}

Household intertemporal optimization concerns consum ption and savings, not their transfers to other agents. Now, with the exception of transfers to govern ment, household transfers in PEP-1- $t$ are a fixed proportion of disposable income, as described in model equations M 047 and M 048.

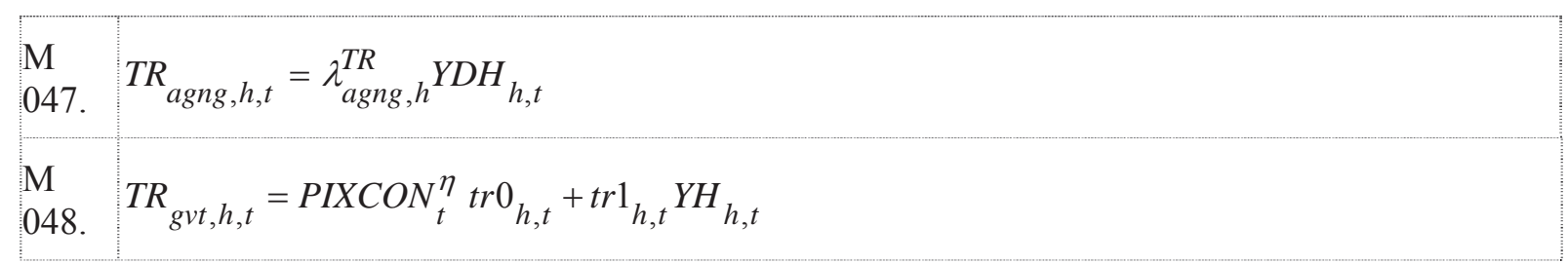

where

$\eta: \quad$ Price elasticity of indexed transfers and parameters

$\operatorname{PIXCON}_{t}:$ Consumer price index

$\operatorname{tr} 0_{h, t}: \quad$ Intercept (transfers by type $h$ households to government)

$\operatorname{tr} 1_{h, t}: \quad$ Marginal rate of transfers by type $h$ households to government

$Y D H_{h, t}:$ Disposable income of type $h$ households

So, from equation M 015,

$$
\begin{array}{l|l}
\mathrm{M} & \mathrm{CTH} H_{h, t}=Y D H_{h, t}-S H_{h, t}-\sum_{\text {agng }} T R_{\text {agng }, h, t}
\end{array}
$$

we define a concept of household disposable income net of transfers as

iii $Y 02$. $Y H_{h, t}-\sum_{\text {agng }} T R_{\text {agng }, h, t}=C T H_{h, t}+S H_{h, t}$

Household disposable income net of transfers is de composed into (i) disposable income from capital, defined as

$$
\begin{aligned}
& \mathrm{M} \\
& \text { 111. }
\end{aligned} \mathrm{PDHK}_{h, t}=\left(1-t t d h 1_{h, t}\right) Y H K_{h, t}
$$

and (ii) disposable income from other sources, net of transfers, defined as 
$\mathrm{M}_{112 .} \mathrm{IDHX}_{h, t}=\left(1-t t d h 1_{h, t}\right)\left(Y H_{h, t}-Y H K_{h, t}\right)-t t d h 0_{h, t} \operatorname{PIXCON}_{t}^{\eta}-\sum_{a g} T R_{a g, h, t}$

where

$\operatorname{ttdh} 0_{h, t}:$ Intercept (income taxes of type $h$ households)

$t t d h 1_{h, t}:$ Marginal income tax rate of type $h$ households

Using equation M 048 and

\begin{tabular}{l|l}
$\mathrm{M}$ & TR \\
047. & $\lambda_{\text {agng }, h, t}^{T R}$ \\
agng, $h$ & $Y D H_{h, t}$
\end{tabular}

It is easily verified that the sum of the two is indeed $Y D H_{h, t}-\sum_{\text {agng }} T R_{a g n g, h, t}$. Combining with

M $\mathrm{CTH}_{h, t}=\mathrm{YDH}_{h, t}-S H_{h, t}-\sum_{\text {agng }} T R_{\text {agng }, h, t}$

where

$\mathrm{CTH}_{h, t}$ : Consumption budget of type $h$ households

we have

iii ODDHK $_{h, t}+\mathrm{YDHX}_{h, t}=\mathrm{CTH}_{h, t}+\mathrm{SH}_{h, t}$

\subsection{Rates of return and the interest rate}

We define the gross (before taxes and depreciation) household rate of return on capital as

M $\quad R R K_{h, t}=\frac{Y H K_{h, t}}{K W_{h, t}}$

From equations M 012 and M 116, $R R K_{h, t}$ is a weighted average of return rates $\frac{R_{k, j, t}}{P K_{t}^{P R I}}$,

iii $\quad R R K_{h, t}=\sum_{k, j} \frac{R_{k, j, t}}{P K_{t}^{P R I}} \frac{\lambda_{h, k, t}^{R K} K D_{k, j, t}}{\sum_{k j, j j}\left(\lambda_{h, k j, j t}^{R K} K D_{k j, j j, t}\right)}$

where the weights are the shares of cap ital by type $k$ and industry $j$ in household $h$ 's wealth. We also define the after-tax rate of return as 
135. $R H O_{h, t}=\left(1-t t d h 1_{h, t}\right) R R K_{h, t}$

Finally, applying theoretical equation [ttt028],

$$
\left(1+r_{t}\right)=\left(1+\rho_{t+1}-\delta\right) g_{p k, t}=\left(1+\rho_{t+1}-\delta\right)\left(1+\pi_{p k, t}\right)
$$

we define the interest rate as

$$
129 . \quad I R_{t}=\left[1+\frac{\sum_{h}\left[g_{h, t}^{R R K} R R K_{h, t} K W_{h, t}\right]}{\sum_{h} K W_{h, t}}-\delta\right] g_{t}^{P K_{-} P R I}-1
$$

where $g_{t}^{P K}{ }_{-}^{P R I}$ and $g_{t}^{R R K}$ are growth factors. The only difference with [ $\mathrm{ttt} 028$ ] is the middle term in the expression between square brackets. In the theor etical model, there is a sin gle household, but in PEP1-t, there $\mathrm{m}$ ay be more than one (however, in the application to South A frica, there is onl y one). Consequently, the theoretical rate of return $\rho_{t+1}$ is replaced by a weighted average. The gro wth factors $g_{t}^{P K_{-} P R I}$ and $g_{t}^{R R K}$ are defined as

$$
\begin{aligned}
& \text { 131. } g_{t}^{P K_{-} P R I}=\frac{P K_{t+1}^{P R I}}{P K_{t}^{P R I}} \\
& \mathrm{M} \quad g_{h, t}^{R R K}=\frac{R R K_{h, t+1}}{R R K_{h, t}}
\end{aligned}
$$

These are to be explained below.

The definition of interest rate $I R_{t}$ is a significant dif ference in PEP-TRE relative to the basic version of PEP-1-t. In the latter, the rate of interest is $m$ erely a rationing device that equates the dem and for investment with the am ount of savings. It has no other role in $t$ he model. Here, however, it $m$ ust be consistent with the rate of return on household wealth: it is indee d the rate of interest that households must receive to be persuaded to invest their savings. Since the rate of interest is no longer fre e to play its role as a rationing devic e, that role must be assumed by another variable. Consequently, the scale parameter in the investment equation becomes a scale variable ${ }^{12}$ :

12 The reader familiar with PEP-1-t will have noticed that in the latter, $\phi$ is indexed in $k$ and $j$. In practice however, the PEP-1- $\mathrm{t}$ calibration procedure results in u niform values for $\phi_{k, j}$. Under those circumstances, it can be shown that it is indifferent to use the interest rate or $\phi$ as the savings-investment equilibrating (rationing) device. See Appendix for details. 
$\mathrm{M} I N D_{k, b u s, t}=\phi_{t}\left[\frac{R_{k, b u s, t}}{U_{k, b u s, t}}\right]^{\sigma_{k, b u s}^{I N V}} K D_{k, b u s, t}$

where

$\phi_{t}: \quad$ Scale parameter (allocation of investment to industries)

$U_{k, j, t}: \quad$ User cost of type $k$ capital in industry $j$

\subsection{Household savings}

We now proceed to identify the theoretical concepts in the net savings equation derived from [ttt018]

$$
s_{t}=p_{k, t}\left(k_{t+1}-k_{t}\right)=\left(\rho_{t}-\delta\right) p_{k, t} k_{t}+y_{t}-p_{c, t} c_{t}
$$

Reorganize [iii 003] as

$$
\text { iii } \mathrm{SH}_{h, t}=\mathrm{YDHK}_{h, t}+\mathrm{YDHX} \mathrm{X}_{h, t}-\mathrm{CTH}_{h, t}
$$

parallel to [ttt019]. The savings concept represented by the left-hand side of [iii 005], however, is gross household savings $(g h s)$. The corresponding theoretical variable would be

$$
\begin{aligned}
& g h s_{t}=s_{t}+\delta p_{k, t} k_{t}=p_{k, t}\left(k_{t+1}-k_{t}\right)+\delta p_{k, t} k_{t}=\rho_{t} p_{k, t} k_{t}+y_{t}-p_{c, t} c_{t} \\
& g h s_{t}=s_{t}+\delta p_{k, t} k_{t}=p_{k, t}\left[k_{t+1}-(1-\delta) k_{t}\right]=\rho_{t} p_{k, t} k_{t}+y_{t}-p_{c, t} c_{t}
\end{aligned}
$$

Its equivalent in PEP-1-t is found by combining equations M 111, M 113 and M 135,

\begin{tabular}{l|l|}
\hline M & $Y D H K_{h, t}=\left(1-t t d h 1_{h, t}\right) Y H K_{h, t}$ \\
\hline M & $R R K_{h, t}=R R K_{h, t}^{D I R}=\frac{Y H K_{h, t}}{K W_{h, t}^{D I R}}$ \\
\hline 113. & $R H O_{h, t}=\left(1-t t d h 1_{h, t}\right) R R K_{h, t}$ \\
\hline 135. &
\end{tabular}

and substituting into [iii 005] to obtain

iii $\quad S H_{h, t}=R H O_{h, t} K W_{h, t}+Y D H X_{h, t}-C T H_{h, t}$ 


\subsection{Household wealth accumulation}

Let us now concentrate on the definition of gross savings in terms of wealth accumulation, as expressed in the first two equalities of [ttt046]

$$
g h s_{t}=s_{t}+\delta p_{k, t} k_{t}=p_{k, t}\left[k_{t+1}-(1-\delta) k_{t}\right]=\rho_{t} p_{k, t} k_{t}+y_{t}-p_{c, t} c_{t}
$$

In the equation above, gross household savings are defined as the difference bet ween the stock of capital owned in $t+1, k_{t+1}$, and the stock of capital owned in $t$ after depreciation, $(1-\delta) k_{t}$, both valued at the current price in period $t$. To relate these to PEP-1-t variables, we begin with $\mathrm{t}$ he definition of household wealth given above,

$$
\text { M } \quad K W_{h, t}=P K_{t}^{P R I} \sum_{k, j}\left(\lambda_{h, k, t}^{R K} K D_{k, j, t}\right)
$$

Using

$$
\mathrm{M}_{121 .} \lambda_{h, k, t+1}^{R K}=\frac{\lambda_{h, k, t}^{R K} \sum_{j}\left[\left(1-\delta_{k, j}\right) K D_{k, j, t}\right]+\left(\frac{S H_{h, t}}{I T_{t}}\right) \sum_{j} I N D_{k, j, t}}{\sum_{j}\left[\left(1-\delta_{k, j}\right) K D_{k, j, t}\right]+\sum_{j} I N D_{k, j, t}}
$$

we can write, from equation M 116,

\begin{tabular}{l|l} 
iii $\quad K W_{h, t+1}=P K_{t+1}^{P R I} \sum_{k, j}\left(\frac{\lambda_{h, k, t}^{R K} \sum_{j j}\left[\left(1-\delta_{k, j j}\right) K D_{k, j j, t}\right]+\left(\frac{S H_{h, t}}{I T_{t}}\right) \sum_{j j} I N D_{k, j j, t}}{\sum_{j j}\left[\left(1-\delta_{k, j j}\right) K D_{k, j j, t}\right]+\sum_{j j} I N D_{k, j j, t}} K D_{k, j, t+1}\right)$ \\
$0008 . \quad K W_{h, t+1}=P K_{t+1}^{P R I} \sum_{k}\left(\frac{\lambda_{h, k, t}^{R K} \sum_{j j}\left[\left(1-\delta_{k, j j}\right) K D_{k, j j, t}\right]+\left(\frac{S H_{h, t}}{I T_{t}}\right) \sum_{j j} I N D_{k, j j, t}}{\sum_{j j}\left[\left(1-\delta_{k, j j}\right) K D_{k, j j, t}\right]+\sum_{j j} I N D_{k, j j, t}} K D_{k, j, t+1}\right)$
\end{tabular}

Substituting from equation M 103,

$$
\text { 103. } K D_{k, j, t+1}=K D_{k, j, t}\left(1-\delta_{k, j}\right)+I N D_{k, j, t}
$$


we find

$$
\text { iii } \quad K W_{h, t+1}=P K_{t+1}^{P R I} \sum_{k}\left[\lambda_{h, k, t}^{R K} \sum_{j j}\left[\left(1-\delta_{k, j j}\right) K D_{k, j j, t}\right]+\left(\frac{S H_{h, t}}{I T_{t}}\right) \sum_{j j} I N D_{k, j j, t}\right]
$$

We now introduce the simplifying assumption that all rates of depreciation are equal, so that

iii $010 . \quad K W_{h, t+1}=(1-\delta) P K_{t+1}^{P R I} \sum_{k, j} \lambda_{h, k, t}^{R K} K D_{k, j, t}+P K_{t+1}^{P R I}\left(\frac{S H_{h, t}}{I T_{t}}\right) \sum_{k, j} I N D_{k, j, t}$

Using wealth definition M 116, together with equation [iii 001]

$$
\text { iii } I T_{t}=P K_{t}^{P R I} \sum_{k, j} I N D_{k, j, t}
$$

and substituting into [iii010], we obtain

\begin{tabular}{l|l|l} 
1ii & $K W_{h, t+1}=(1-\delta) \frac{P K_{t+1}^{P R I}}{P K_{t}^{P R I}} K W_{h, t}+S H_{h, t}$ \\
0112. & $S H_{h, t}=\frac{P K_{t}^{P R I}}{P K_{t+1}^{P R I}} K W_{h, t+1}-(1-\delta) K W_{h, t}$ \\
0 & iii
\end{tabular}

Indeed, in accordance with theoretical equation [ttt046], $\mathrm{SH}_{h, t}$ is gross household savings.

\subsection{Household dynamic budget constraint}

From [iii 012], substitute for $S H_{h, t}$ into

$$
\text { iii } \quad S H_{h, t}=R H O_{h, t} K W_{h, t}+Y D H X_{h, t}-C T H_{h, t}
$$

using

$$
\text { M } g_{t} P K_{-} P R I=\frac{P K_{t+1}^{P R I}}{P K_{t}^{P R I}}
$$

and there results 
\begin{tabular}{l|l|} 
iii & $\frac{1}{g_{t}^{P K_{-} P R I}} K W_{h, t+1}-(1-\delta) K W_{h, t}=R H O_{h, t} K W_{h, t}+Y D H X_{h, t}-C T H_{h, t}$ \\
\hline iii & $C T H_{h, t}=\left(1+R H O_{h, t}-\delta\right) K W_{h, t}+Y D H X_{h, t}-\frac{1}{g_{t}^{P K} P R I} K W_{h, t+1}$
\end{tabular}

Equation [iii 014] is the household dynamic budget constraint. It is the PEP-1-t equivalent of

$$
p_{c, t} c_{t}=\left(1+\rho_{t}-\delta\right) p_{k, t} k_{t}+y_{t}-p_{k, t} k_{t+1}
$$

which is the theoretical dynamic budget constraint derived from

$$
s_{t}=p_{k, t}\left(k_{t+1}-k_{t}\right)=\left(\rho_{t}-\delta\right) p_{k, t} k_{t}+y_{t}-p_{c, t} c_{t}
$$

\subsection{Truncated rational expectations}

Until now, we have not specified expectations. We now proceed with the model under truncated rational expectations (TRE). In the TRE framework, households have rational expectations for the current period and the following one. Accordingly, the model is solved simultaneously for two periods at a time, the current period $\tau$ and the following per iod $\tau+1$. Household (rational) expectations for period $\tau+1$ are given by the model solution. For subsequent periods, household expectations are formed by extrapolating from $\tau$ and $\tau+1$ solution values, assu ming a constant rate of change. With these extrapolations, the intertemporal problem to any planning horizon $T$ is entirely endogenous to the two-period model.

So the model is solved iteratively for successive pairs of periods: solve for periods 0 and 1 and keep the period 0 solution; then solve for periods 1 and 2 and keep period 1 solution; next solve for periods 2 and 3 , etc. For each pair [ $\tau, \tau+1]$ of periods, the household solves its intertem poral optimization problem up to its planning horizon (the hous ehold planning horizon moves forward one period each period). But only the first period $(\tau)$ of the program actually gets implem ented. For $\tau+1$, the household applies the first period of the optim al intertemporal program computed as part of the sim ultaneous $[\tau+1, \tau+2]$ model solution. Etc.

\begin{tabular}{|c|c|}
\hline 015 . & $Y D H X_{h, t}=g_{h, \tau}^{Y D H X} Y D H X_{h, t-1}=\left(g_{h, \tau}^{Y D H X}\right)^{t-\tau} Y D H X_{h, \tau}$, for $t \geq \tau$ \\
\hline 016. & 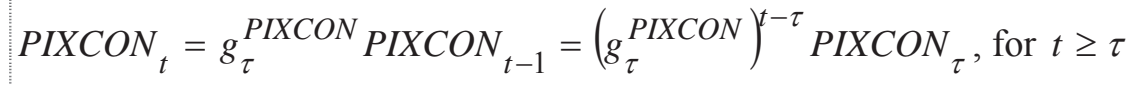 \\
\hline
\end{tabular}

The extrapolation formulae that generate household expectations are: 


\begin{tabular}{l|l|}
\hline iii & $P K_{t}^{P R I}=g_{\tau}^{P K_{-} P R I} P K_{t-1}^{P R I}=\left(g_{\tau}^{P K_{-}}{ }^{P R I}\right)^{t-\tau} P K_{\tau}^{P R I}$, for $t \geq \tau$ \\
\hline iii & $R H O_{h, t}=g_{h, \tau}^{R H O} R H O_{h, t-1}=\left(g_{h, \tau}^{R H O}\right)^{t-\tau} R H O_{h, \tau}$, for $t \geq \tau$
\end{tabular}

where the growth rates are simply

\begin{tabular}{|l|l|}
\hline $\mathrm{M}$ & $g_{h, \tau}^{Y D H X}=\frac{Y D H X_{h, \tau+1}}{Y D H X_{h, \tau}}$ \\
\hline 130. & $g_{\tau}^{P K_{-} P R I}=\frac{P K_{\tau+1}^{P R I}}{P K_{\tau}^{P R I}}$ \\
\hline 131. & $g_{\tau}^{P C}=\frac{P I X C O N_{\tau+1}}{P I X C O N_{\tau}}$ \\
\hline 132. & $g_{h, \tau}=\frac{R H O}{R H, \tau+1}$ \\
\hline 133. & $R O_{h, \tau}$ \\
\hline$M$ &
\end{tabular}

It is im portant to note $t$ hat, under $t$ his formulation, the household's planning horizon is entirely independent from the length of the m odel simulation run. For that reason, the param eter LifeEnd is the number of periods beyond the current one over which households optim ize their consumption. The index Lifetime (alias Lifetoo) designates successive periods of the intertemporal optimization time-span:

Lifetime $=1, \ldots$, LifeEnd

\subsection{Model solution}

Following the procedure outlined in 1.4 above, we obtain the Euler equation

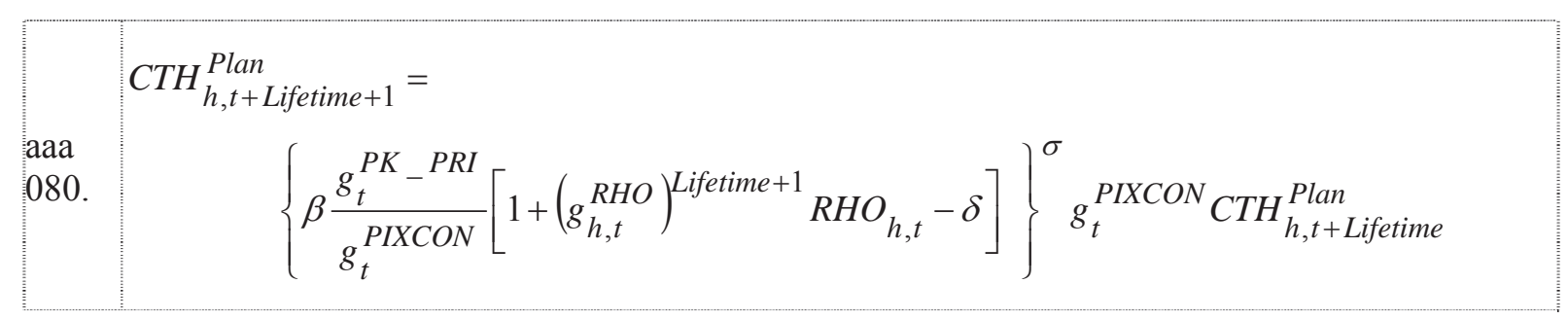

where

Lifetime $=1, \ldots$, LifeEnd 
and $\mathrm{CTH}_{h, t+\text { Lifetime }}^{\text {Plan }}$ represents the amount consumption expenditures planned at time $t$ for future period $t+$ Lifetime. And, by recursion, we obtain the following equation,

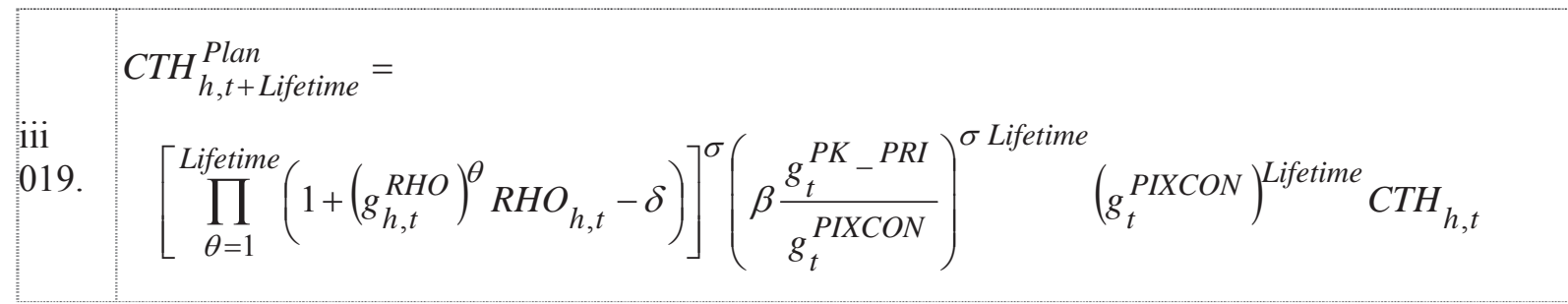

in which the optimal amount of consumption expenditures for any future period up to the household planning horizon is expressed in terms of current values of variables and growth rates. Let

$\mathrm{M}_{125 .} D_{h, \text { Lifetime }, t}=\left(\frac{1}{g_{t}^{P K_{-} P R I}}\right)^{\text {Lifetime }}\left[\prod_{\theta=1}^{\text {Lifetime }}\left(\frac{1}{1+\left(g_{h, t}^{R H O}\right)^{\theta} R H O_{h, t}-\delta}\right)\right]$

and [iii 019] becomes

1ii $\quad$ C20. $H_{h, t+\text { Lifetime }}^{\text {Plan }}=\left(D_{h, \text { Lifetime }, t}\right)-\sigma\left(\frac{\beta}{g_{t}^{\text {PIXCON }}}\right)^{\sigma \text { Lifetime }}\left(g_{t}^{\text {PIXCON }}\right)^{\text {Lifetime }} C T H_{h, t}$

In the two-period sim ultaneous solution of the m odel, equation [iii 020] applied to the second period (Lifetime $=1)$ is

136. $\quad C T H_{h, t+1}^{\text {Plan }}=\left(D_{h, 1, t}\right)^{-\sigma}\left(\frac{\beta}{g_{t}^{\text {PIXCON }}}\right)^{\sigma} g_{t}^{\text {PIXCON } C T H_{h, t}}$

The intertemporal budget constraint at time $t$ is given by

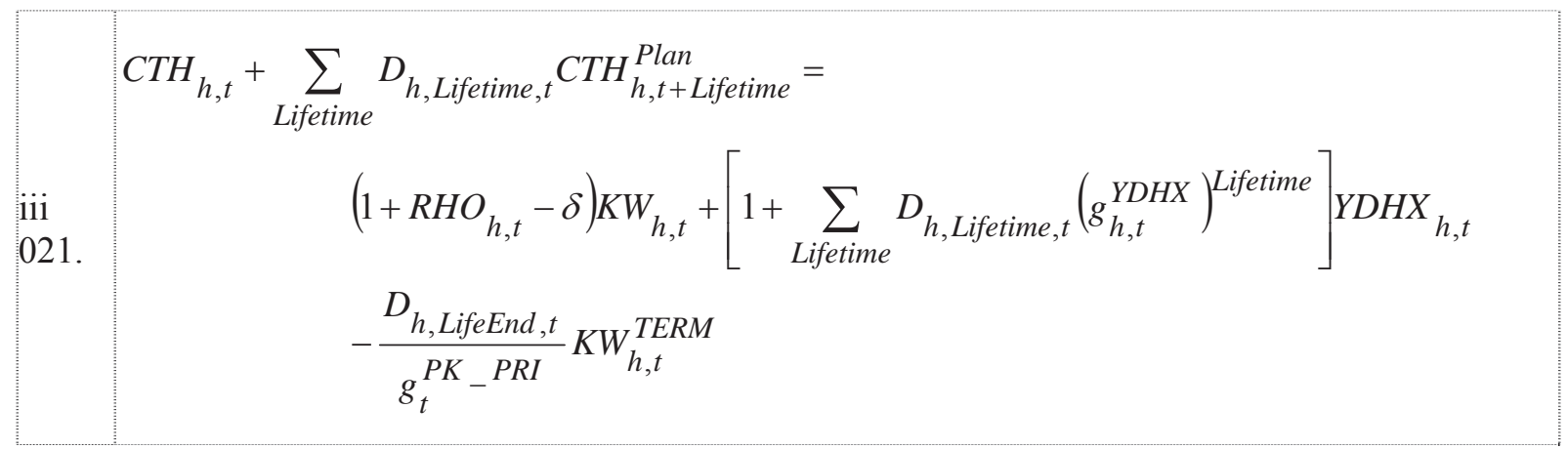

where 
$K W_{h, t}^{T E R M}:$ Terminal wealth used in intertemporal optimization at time $t$ by household $h$; it is the amount of wealth which, according to its plans at time $t$, the households expects to leave at the end of period $t+$ LifeEnd.

This variable defines the transversalit y (No Ponzi game) condition for each period' $\mathrm{s}$ intertermporal optimization exercise. Substitute [iii 020] into intertemporal budget constraint [iii 021] and find

\begin{tabular}{|c|c|c|c|}
\hline $\begin{array}{l}1 i i \\
022 .\end{array}$ & $\begin{array}{r}C T H_{h, t}+\sum_{\text {Lifetime }}\left(D_{h, \text { Lifetime }, t}\right)^{1-\sigma} \frac{\beta}{g_{t}^{\text {PIXCON }}} \\
\left(1+R H O_{h, t}-\delta\right) K W_{h, t}+ \\
-\frac{D_{h, \text { LifeEnd }, t}}{g_{t}^{P K_{-} P R I}} K W_{h, t}^{T E R M}\end{array}$ & $\begin{array}{l}\int^{\sigma \text { Lifetime }}\left(g_{t}^{\text {PIXCON }}\right)^{\text {Lifetime }} C T H_{h, t}= \\
{\left[1+\sum_{\text {Lifetime }} D_{h, \text { Lifetime }, t}\left(g_{h, t}^{Y D H X}\right)^{\text {Lifetime }}\right.}\end{array}$ & $\int^{Y D H X_{h, t}}$ \\
\hline
\end{tabular}

Let

\begin{tabular}{l|l|}
$\mathrm{M}$ & $Z 1_{h, t}=1+\sum_{\text {lifetime }=1}^{\text {LifeEnd }} D_{h, \text { lifetime }, t}\left(g_{h, t}^{\text {YDHX }}\right)^{\text {lifetime }}$ \\
\hline 127. & $Z 2_{h, t}=1+\sum_{\text {lifetime }=1}^{\text {EndLife }}\left(D_{h, \text { lifetime }, t}\right)^{1-\sigma}\left(\frac{\beta}{g_{t}^{\text {PIXCON }}}\right)^{\text {Olifetime }}\left(g_{t}^{\text {PIXCON }}\right)^{\text {lifetime }}$
\end{tabular}

and [iii 022] becomes

$$
\mathrm{M}_{128 .} \mathrm{CTH} H_{h, t}=\frac{1}{Z 2_{h, t}}\left[\left(1+R H O_{h, t}-\delta\right) K W_{h, t}+Z 1_{h, t} Y D H X_{h, t}-\frac{D_{h, \text { LifeEnd }, t}}{g_{t}^{\text {PK_PRI }}} K W_{h, t}^{\text {TERM }}\right]
$$

This is the new consumption equation in PEP-TRE. Equation M 128, however, applies only to the first of the moving two-period simultaneous solution of the model. For second-period consumption expenditures, equation M 136 is used. Apply ing M 128 to the s econd period yields a solution that is only slightly different, but is inconsistent with the view that households $\mathrm{m}$ ake their decisions in the first period with perfect foresight regarding the second.

What remains to be defined is how terminal wealth (the transversality condition) is determined. In the current version of PEP-TRE, we assu me that the household wants term inal wealth per capita to be equal 
to its initial wealth in real term s. Here, « in real terms » is to be understood as meaning with the same consumer purchasing power.

120. $K W_{h, t}^{\text {TERM }}=\operatorname{pop}_{t} K W_{h, t}^{O} \operatorname{PIXCON}_{t}\left(g_{t}^{\text {PIXCON }}\right)^{\text {Lifetime }}$

\subsection{Model summary}

Table 1 below su mmarizes the differences in PEP-TRE relative to the standard version of PEP1-t. Red markings highlight changes that are visually less obvious. 
กี

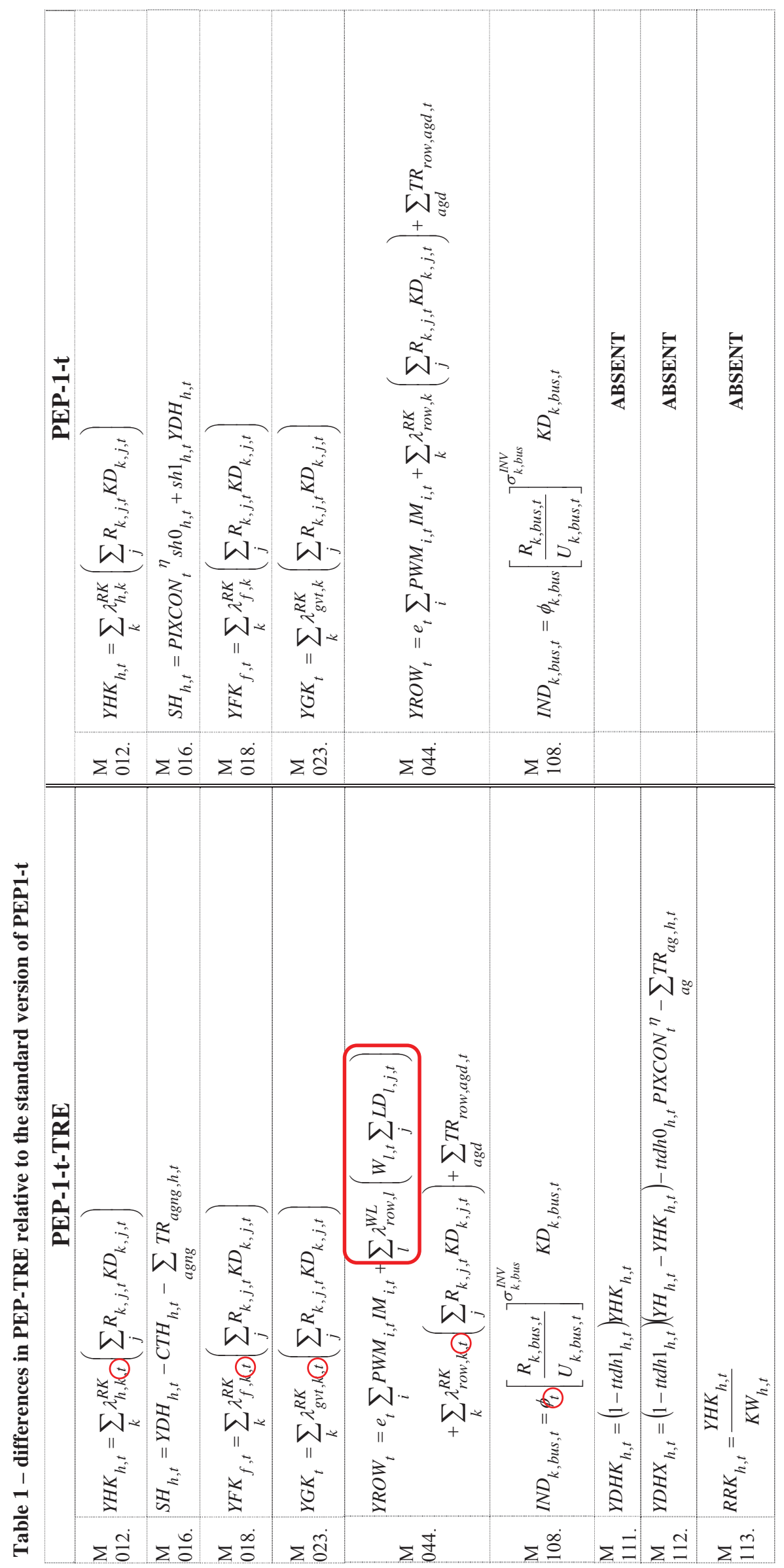


$m$
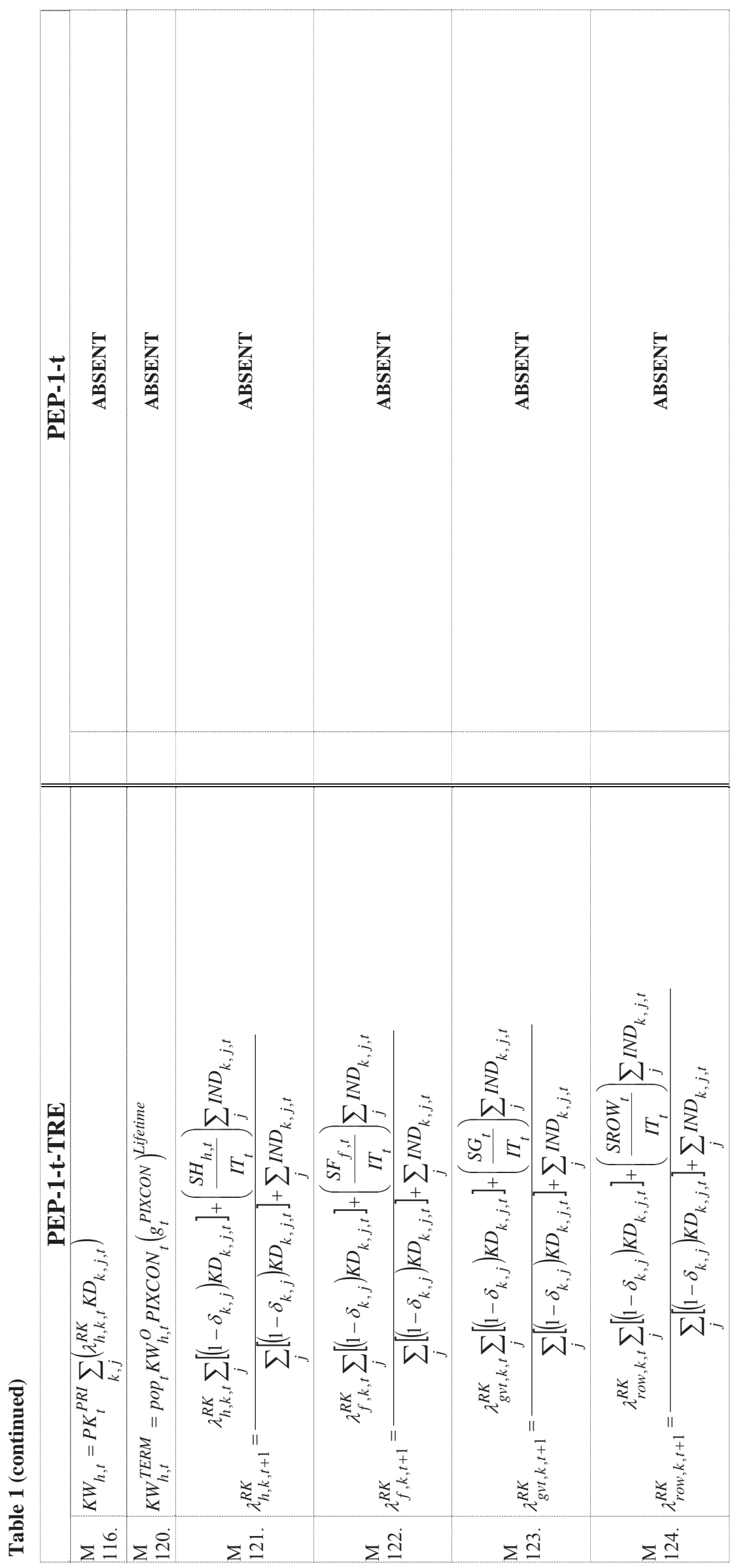
ষ
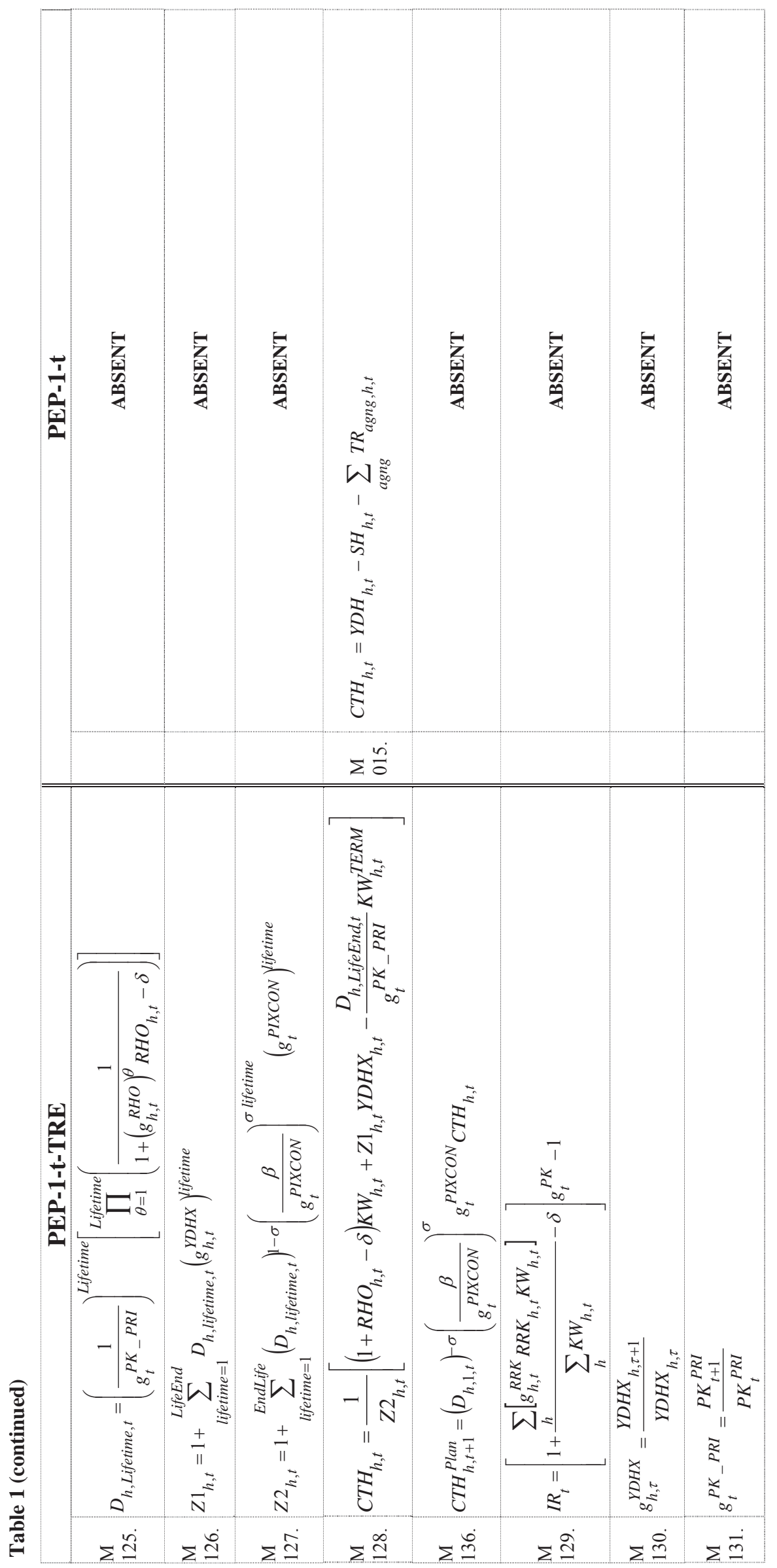
$\approx$

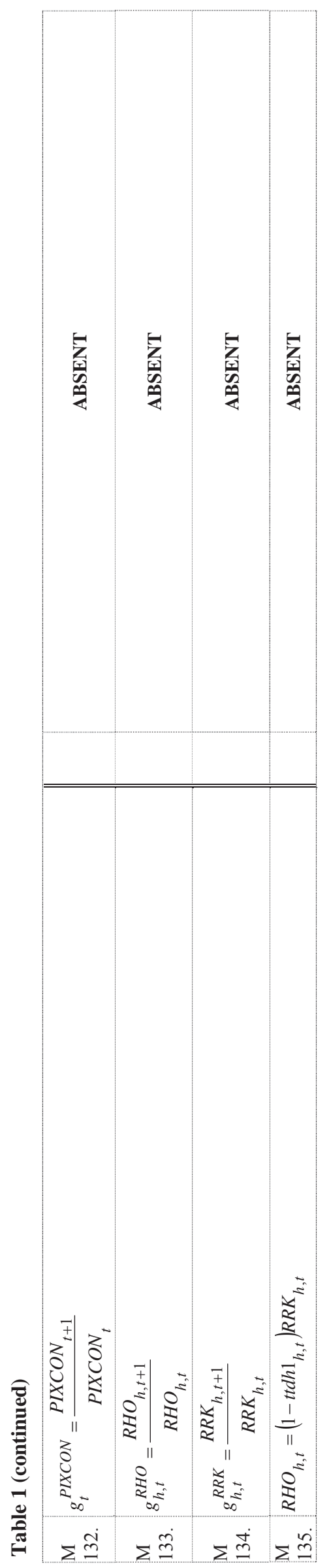




\section{Application to South Africa, 2005}

\subsection{SAM}

The PEP-TRE model is applied to South Africa. Sp ecifically, we use the 2005 South African SAM by Davies and Thurlow (2011) ${ }^{13}$. The SAM was first converted to the PEP-1-t form at and aggregated (see appendix for the list of industries/commodities).

Next, inventory changes in the SAM were elim inated. This was not done only for convenience. Indeed, inventory variations are notoriously volatile, and for that reason difficult to model in a CGE. In particular, if inventory changes are to be $\mathrm{m}$ odelled as a pa rticular form of investm ent, then, no matter how reasonable the model may be, its calib ration is highly dependent on business cy cle conditions at the moment the SAM was co nstructed. Modellers often choose to fix inventor y variations exogenously, but the idea that surplus production can be dum ped indefinitely to inventory stretches the i magination, and even more so the idea that supply can be pum ped indefinitely out of inventories. To eliminate inventory variations, using PEP-1-1, we conduc ted a static simulation of the model in which inventory variation is exogenously fixed at zero. The resulting solution was then used to construct a new base-year SAM ${ }^{14}$.

We use two variants of the SAM. The first is the original Davies and Thurlow SAM, except for the elimination of inventory variations. But in that SA M, the household savings rate is very low (2.6\% of disposable income net of transfers to other agents ${ }^{15}$ ). The objective in constructing a second variant of the SAM was to have an example, albeit artificial, of an economy where the household savings rate is high, in order to determine the implications of the initial savings rate on the endogenous evolution of the savings rate in the model. We constructed an alternate SA $\mathrm{M}$, with a household savings rate of $16.8 \%$. This was achieved by setting firm savings in the original SA M to zero, and increasing household s avings by the same amount, while balancing accounts by adding an equivalent transfer from firms to households (these transfers may be interpreted as dividends). The resulting SAM is our second variant, which is identical to the original one in every other aspect. The two variants are nicknamed LoSH (low household savings) and HiSH (high household savings).

13 Thanks to Hélène Maisonnave, who has kindly transmitted to us the 2005 So uth African SAM. That SAM is no longer available on the IFPRI website; it has been replaced by a 2009 SAM. The reason for using the 2005 one will be explicited shortly.

14 This is in fact the reason wh y PEP-TRE was not applied to Senegal as initially planned. When inventory changes were eliminated using the same technique for Senegal, the resulting SAM was so radically different from the initial one that it could hardly be considered to represent the same economy. As a matter of fact, inventory changes in the origin al Senegal SAM were so important that the model had to be solved several times to eliminate them in slices. 


\subsection{Parametrization}

Parametrizing PEP-TRE poses quite a challenge. From the model summary in Table 1, it can be seen that the five growth factors defined in equations M 130-M 134 appear critically in the household intertemporal optimization equations M 120 and M 125-M 129. With a single observation year (the SAM), these growth rates are unknown, and with unknown growth factors, the $\mathrm{m}$ odel cannot be calibrated. Moreover, the intertemporal rate of substitution $\sigma$ and the psychological discount factor $\beta=1 /(1+\psi)$, which appear in equation M 127, are free parameters (as are, for instance, CES elasticities of substitution).

We applied a parametrization procedure that can be summarized as follows.

1. Set the values of all growth factors provisionally to 1 .

2. After everything else has been calibrated, compute $Z 2_{h}^{O}$ by inverting equation M 128 :

$$
\text { 023. } \quad Z 2_{h, t}=\frac{1}{C T H_{h, t}}\left[\left(1+R H O_{h, t}-\delta\right) K W_{h, t}+Z 1_{h, t} Y D H X_{h, t}-\frac{D_{h, \text { LifeEnd }, t}}{g_{t}^{P K_{-} P R I}} K W_{h, t}^{\text {TERM }}\right]
$$

3. Set the intertemporal rate of substitution from the literature; here we use $\sigma=0.35$.

4. Solve equation M 127 as an implicit equation for $\beta$.

At that point, the model is fully parametrized for growth factors equal to 1 . Then,

5. Solve the model simultaneously for periods 1 and 2 (2005 and 2006).

6. The model solution will be consistent with the first-year values, but the growth factors computed from the second-year solution will be different from their provisional values.

7. Fix the growth factors at their solution values and re-calibrate all variables that depend on them.

8. Return to step 5 and repeat until the solution values of the growth factors are equal to their provisional values.

The procedure may require slicing the adjustments in step 7 . When slicing, rather than settin $g$ the growth factors at their solution va lues, they are fixed as a linear co mbination of their previous values and their solution values; in so me instances, the weight of th e solution value had to be as low as 0.1 . In the application to South Africa, this procedure, with slicing, generally necessitated between 35 and 40 solutions before converging.

$15 S H_{h}^{O} /\left(Y D H K_{h}^{O}+Y D H X_{h}^{O}\right)$ 


\subsection{Closure}

The model closure is standard. The exchange rate is the numeraire. The curren $t$ account balance is fixed exogenously and grows at the same rate as population. The same applies to the labor supply, government savings, and public investment. The rate of growth of South African population is set at $1.34 \% 16$.

\subsection{Simulations}

The BAU scenario runs over a 50-year span, to horizon 2054. The household planning horizon is set at 30 years. Given the importance of mining in South Africa, the first "counter-factual" si mulation consists in a permanent $50 \%$ drop in the (exogenous) international price of minerals (products of the industry labeled Mining in our aggregation).

Our second simulation is to test household reaction to a sudden unexpected an d substantial reduction in wealth. It is expected that, faced wit $\mathrm{h}$ such circ umstances, with unchanged transversality condition, households will try to restore their level of wealth and, to do so, will increase their savings. This indeed is how many have interpreted the rise in the U.S. household savings rate after the bottom fell out of the real estate market in 2008. To sim ulate a sudden decline in wealth, the Alice-in-Wonderland shock that was inflicted to households in the model is a confiscation of $20 \%$ of their we alth by government. As we shall see, results were not those expected.

In the third sim ulation, we test the impact on hous ehold savings of a reduction in the rate of return on wealth. It is expected that a lower rate of return is a disincentive for savings. This experiment consists in slapping a $2 \%$ surtax on houseshold capital income in the LoSH case, and a 10\% surtax in the HiSH case. And this time, the result is as expected.

\subsection{Results}

The first result to point out is... that the $\mathrm{m}$ odel actually runs! And it appears to be quite robust. This required several programming adjustments, but $t$ he apparent ease of solution exceeds this author's expectations.

\subsubsection{Simulation 1: permanent 50\% drop in the international price of minerals}

Figure 1 displays the evolution of real GDP at basic prices for each of the four scenarios:

16 http://en.wikipedia.org/wiki/Demographics_of_South_Africa 
- BAU-LoSH is the reference scenario with the original Davies and Thurlow SAM, where the household savings rate is low (LoSH);

- SIM-LoSH is the scenario in which the world price of minerals falls by $50 \%$ in 2006 , with the original Davies and Thurlow SAM, where the household savings rate is low (LoSH);

- BAU-HiSH is the reference scenario with the alternate SAM, where the househ old savings rate is high (HiSH);

- SIM-HiSH is the scenario in which the world price of $m$ inerals falls by $50 \%$ in 2006 , with the alternate SAM, where the household savings rate is high (HiSH).

Figure 1

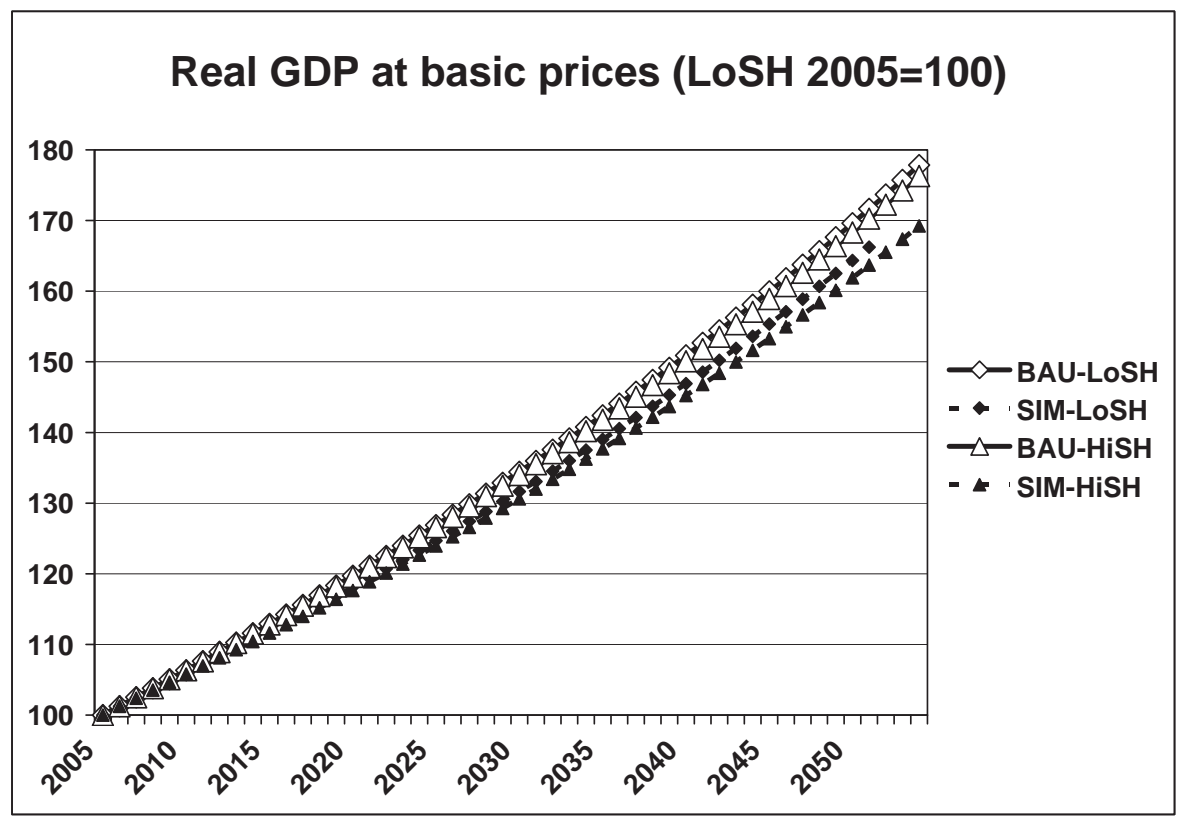

Since labor supply is identical in all fo ur scenarios, and given that real GDP is essentially a measure of the volume of primary factors, then the differences must come from the volume of capital, and $m$ ore specifically from capital accu mulation through (savings-driven) investment. With fixed governm ent savings and current account balance (foreign savings), differences in the volume of capital can only result from differences in real domestic private savings (h ousehold and firm savings, divided by the price of capital). This is shown in Figure 2. 
Figure 2

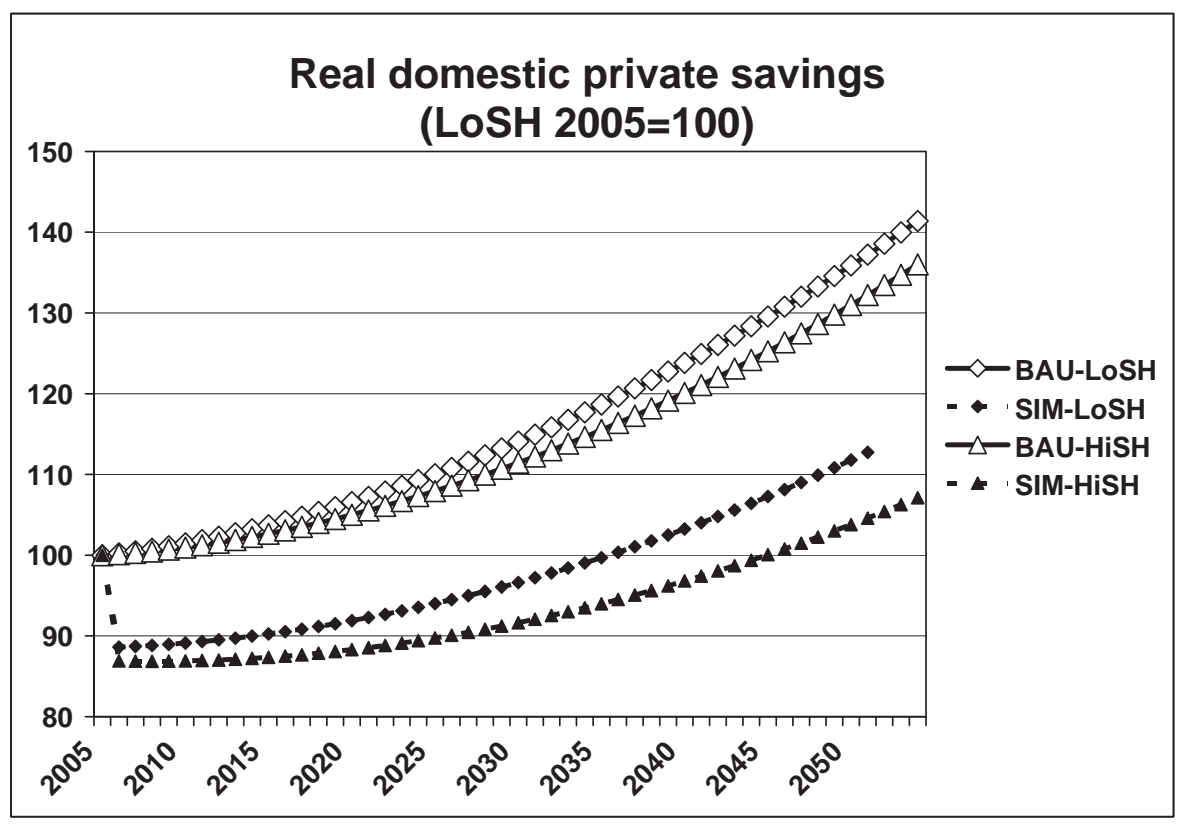

At first sight, one $\mathrm{m}$ ight be surprised that dom estic private savings are lower in the high household savings rate variant (HiSH). Recall however that, in the HiSH variant, firm savings are zero: the am ount that firms would have saved is transferred to households, whose income is consequently higher, leading to more savings. But whereas the firms' contributi on to dom estic savings in the LoSH variant (SF) is mechanically determined as a fraction of firms' disposable income, household savings in both variants are subject to their intertemporal optimization. So what Figure 2 shows is that, when households receive from firms a transfer that is equivalent to what the latter would have saved, they choose to spend part of it on consumption. And that occurs in spite of the fact that the HiSH variant of the model is calibrated so that household savings are initially equal to total domestic private savings in the LoSH variant.

Figure 3 shows the evolution of real household dis posable income, net of transfers. In co nstructing the second variant of the SA M, household income was artificially boosted by a transfer fro $m$ firms equal to their savings in the original SAM. Consequently, household income is higher in the second variant of the SAM and in the HiSH scenarios. In both pairs of scen arios (Lo- and HiSH), the shock on the world price of minerals has a negative impact on household inc ome. But thereafter, household incomes resume their ascent. 


\section{Figure 3}

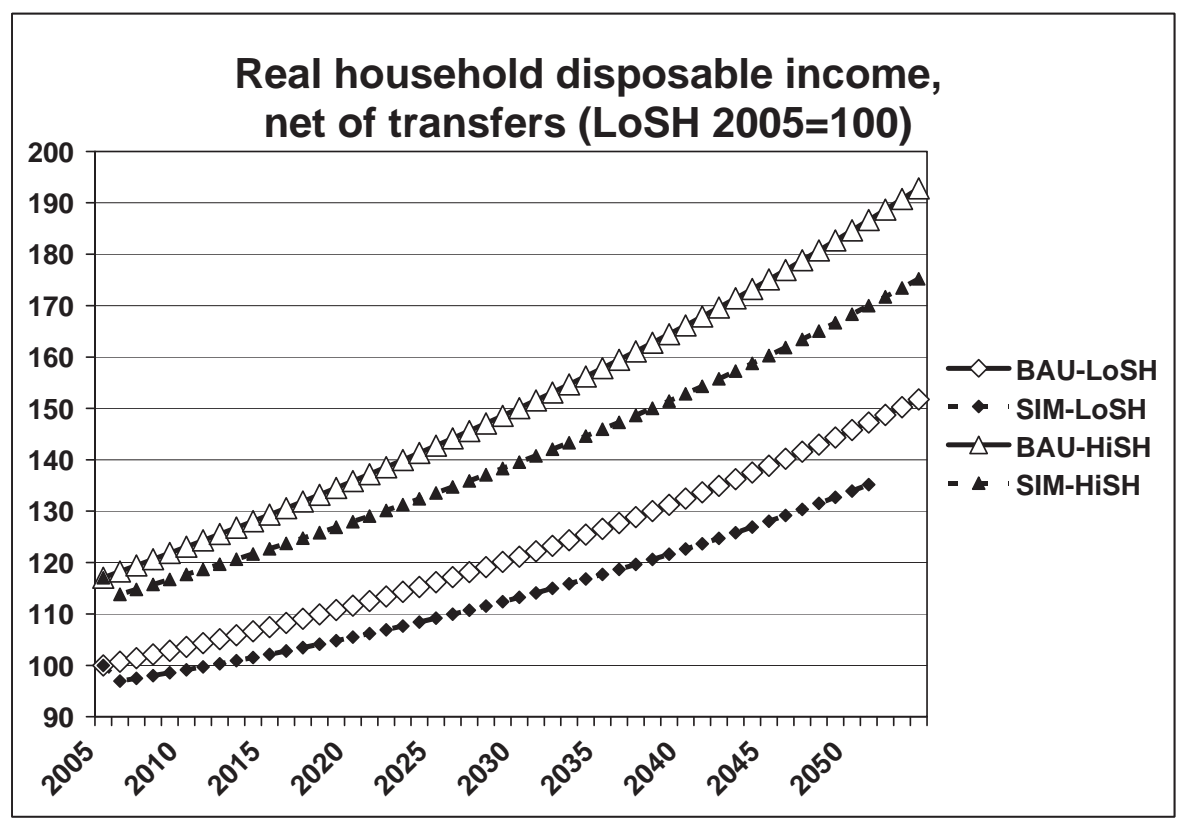

Figure 4 displays the evolution of real household consumption expenditures.

Figure 4

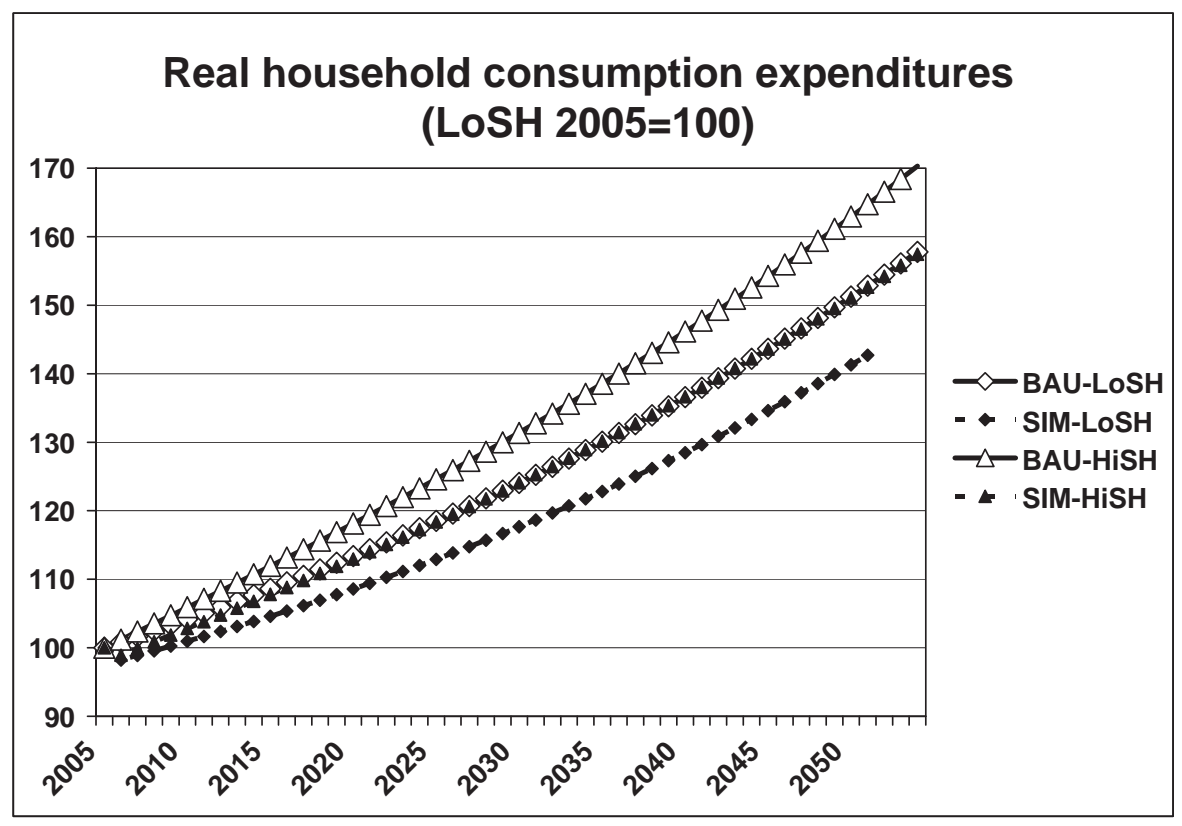

Bringing together Figures 2-4 shows that the income shock of a drop in the international price of minerals is absorbed mostly by a drop in savings, as hous eholds reschedule their lifetim e savings-consumption 
plan ${ }^{17}$. It can be seen that they do not revert progressively to their original plan, but rather se ttle for a lower consumption and savings regime after the shock. $\mathrm{T}$ his is consistent with the model construct, according to which households solve their intertemporal optimization problem afresh every period, on the basis of their currently held expectations, which are projections from a two-period near-perfect foresight.

In Figure 5, it is seen that indeed, both in the high- and in the low-savings rate situation, the savings rate remains indefinitely below what it would have be en without the shock on the international price of minerals. Moreover, in all scenarios, the savings rate falls over time, and in the two LoSH scenarios, it becomes negative.

\section{Figure 5}

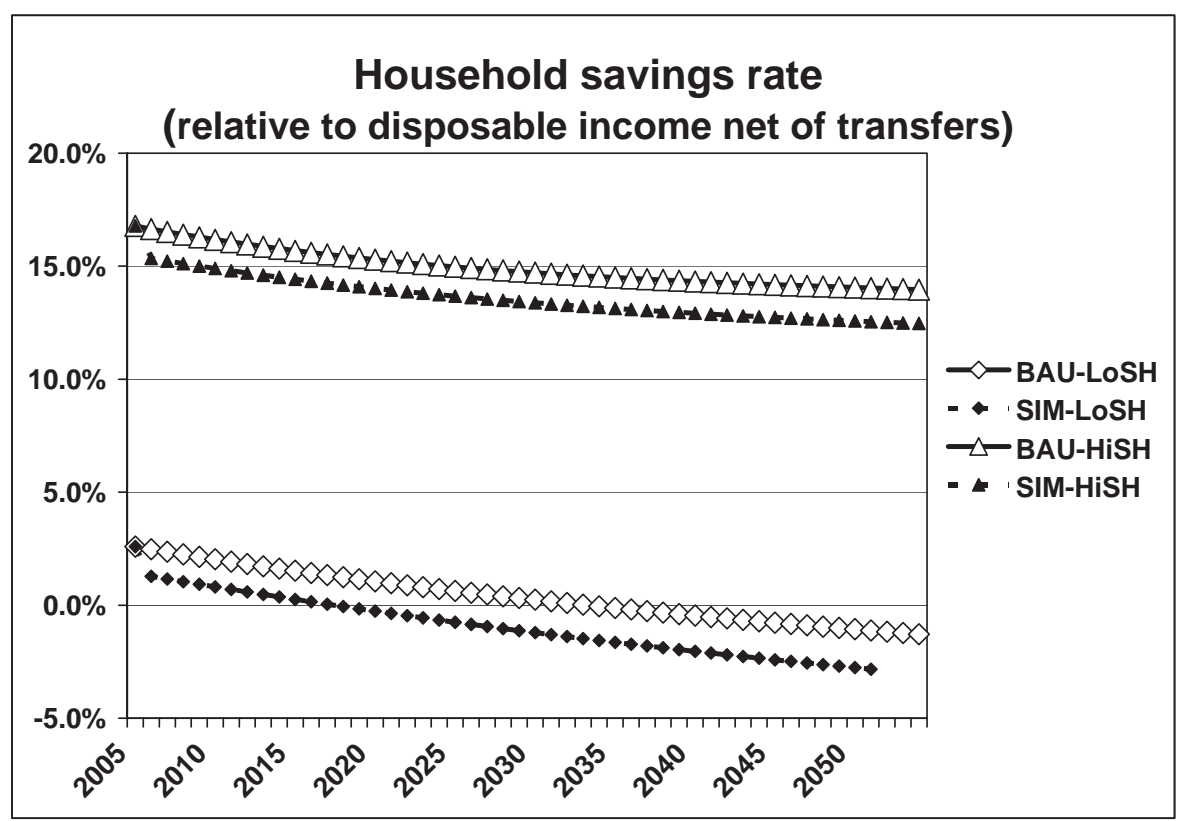

Finally, let us consider the evolution of household wealth. Here, the contrast between initial high- and low savings is striking. In the first case (Figure 6a), although the savings rate declines, households continue to accumulate wealth, albeit at a reduced rate. In the low savings case (Figure 6b, which is the original Davies and Thurlow SAM), savings are insufficient to even maintain the initial level of wealth.

17 Relative to the BAU solution, real savings fall by $11.6 \%$ in the LoSH case, and by $13.2 \%$ in the HiSH case, while real consumption expenditures fall by $2.6 \%$ and $2.2 \%$. It should be kept in mind, however, th at real household co nsumption expenditures are computed here using the consumer price index, while real savings, from the point of view of capital accumulation, are based on the price index of the capital good. And in this particular simulation, under the LoSH case, the shock brings about a 7.4\% fall in the price of capital, but a 9. 5\% drop in consumer prices relative to BAU; under the HiSH case, the reductions are $7.4 \%$ and $9.4 \%$. Therefore, the discrepancy in the proportional reduction of savings and consumption is even greater in nominal than in real terms. In the LoSH case, there is a 55.1\% fall in nominal savings, and a $11.8 \%$ fall in nominal consumption expenditures; the corresponding figures in the HiSH case are $19.6 \%$ and $11.4 \%$. 
Figure 6a

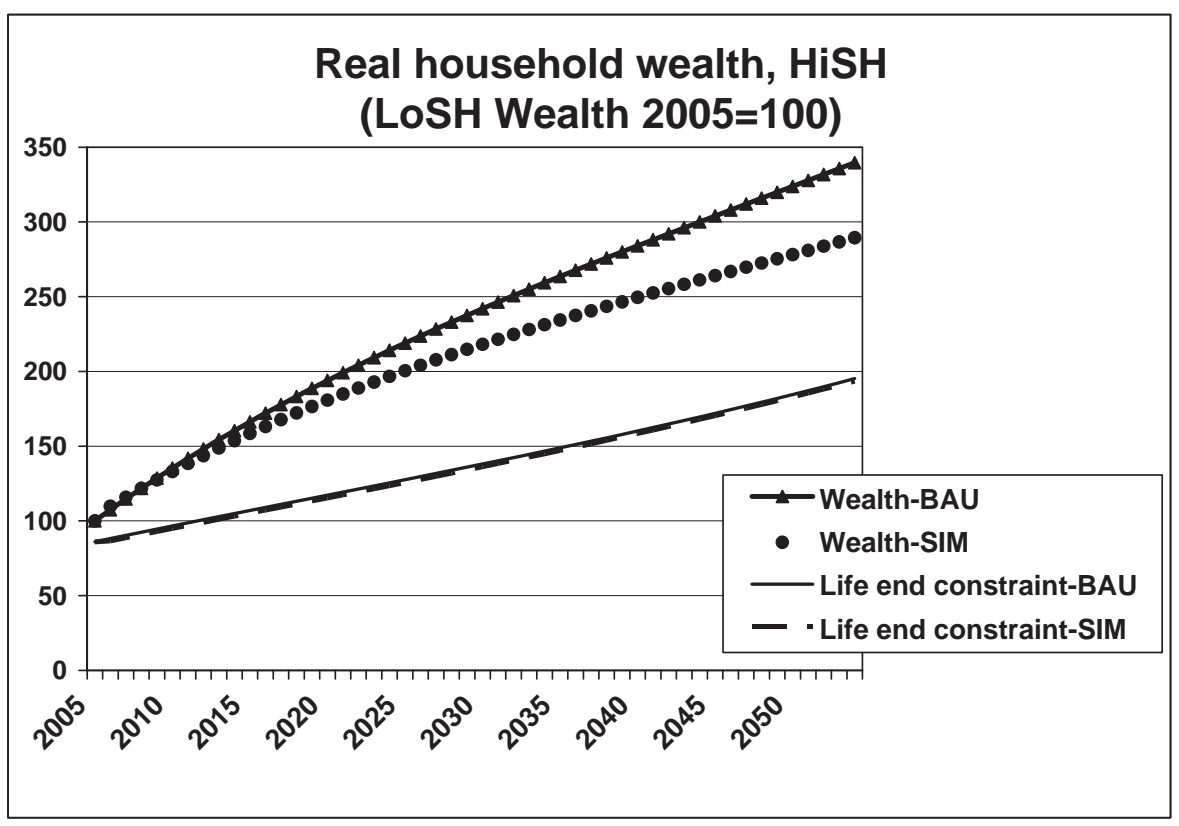

Figure 6b

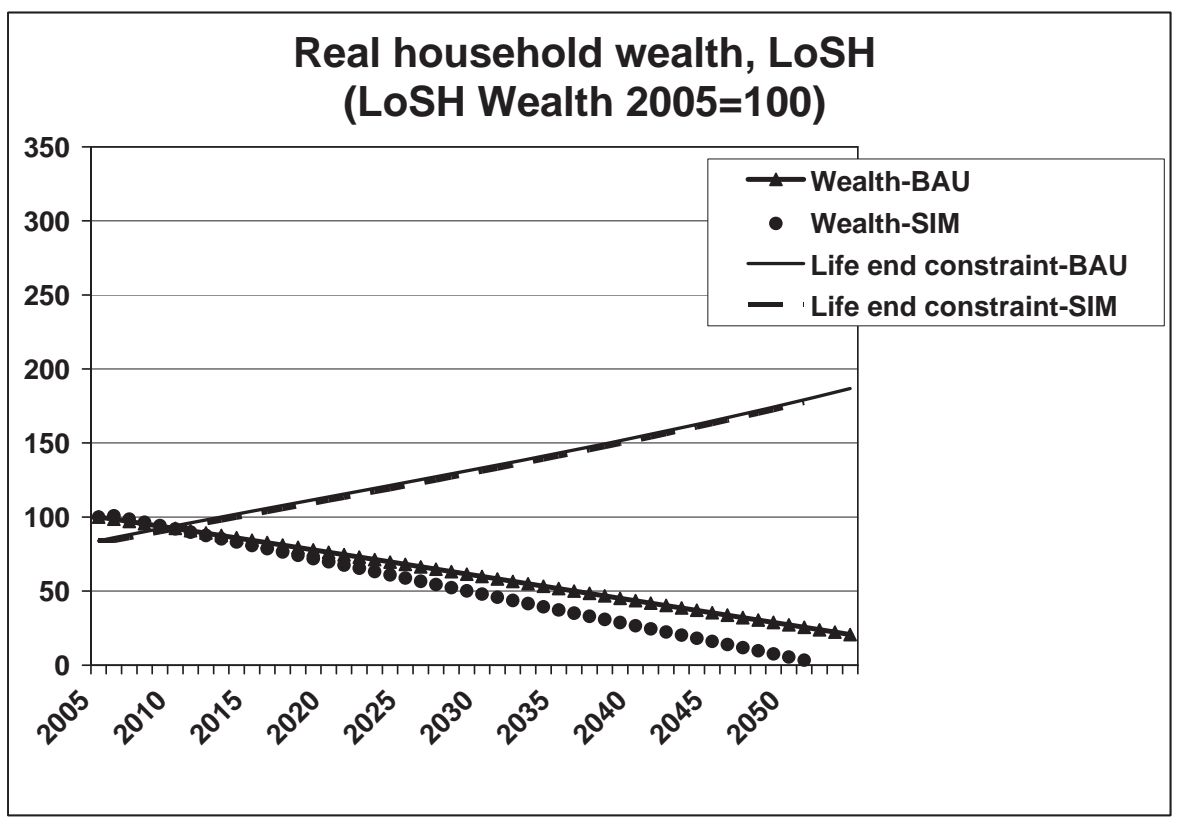


Figures $6 \mathrm{a}$ and $6 \mathrm{~b}$ also display the evolution of terminal wealth (Life end constraint), which defines the transversality (no Ponzi gam e) condition ${ }^{18}$. The terminal wealth constraint evolves according to the assumption that the house hold wants terminal wealth per capita to be equal to its initial wealth in real terms (equation M 120). And, as a matter of fact, the ter minal wealth constraints are virtually identical across scenarios. Initially, real wealth is greater than its target value, because the target value calculation takes into account the expected evolution of consum er prices, which is negative (equation M 120). Both figures show a striking paradox: real wealth m oves away from its target value! In the HiSH case, wealth is already greater initially than prescribed term inal wealth, and it keeps growing faster than the target is raised. In the LoSH case, wealth declin es until it becomes less than term inal wealth, and it continues to fall as the target is raised. How is that possible?

Figure 7 shows how, in the SIM-LoSH scenario, household savings and consum ption plans change over the course of the 2005-2054 sim ulation. The first pa nel displays the savings and consum ption plan as it stands in 2005 for the 2005-2035 period. It calls for small savings with a modest increase over time up to the planning horizon ${ }^{19}$. The three other panels present the thirty -year plans of 2020, 2035 and 2050

\section{Figure 7}

\section{Savings-consumption plan 2005, SIM-LoSH}

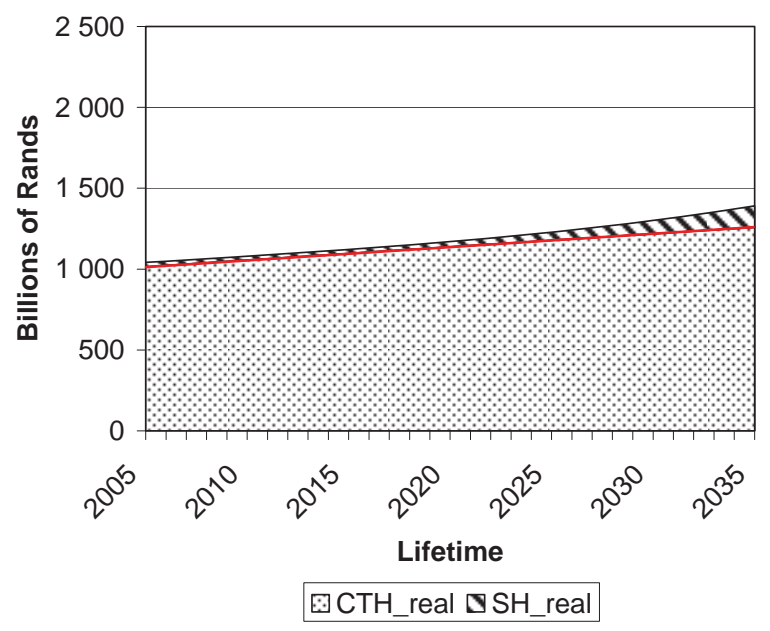

\section{Savings-consumption plan 2020, SIM-LoSH}

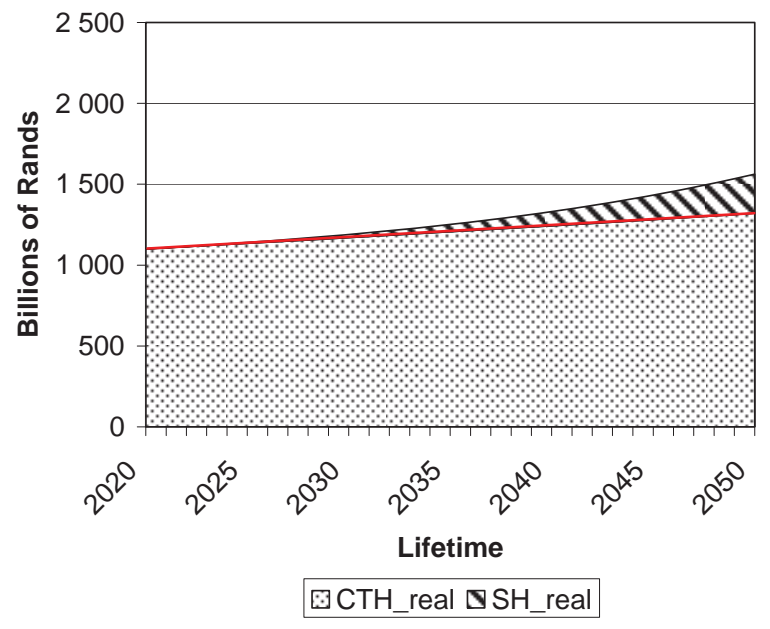

18 Actually, real wealth and terminal wealth constr aint are not really comparable because the latter should be discounted to its present value as it is in equation M 128.

19 The red line is planned consumption expenditures. The hatched area represents savings. When the hatch ed area is below the red expected-income line, as in the left part of the fourth panel (2050), savings are negative. 
Savings-consumption plan 2035, SIM-LoSH

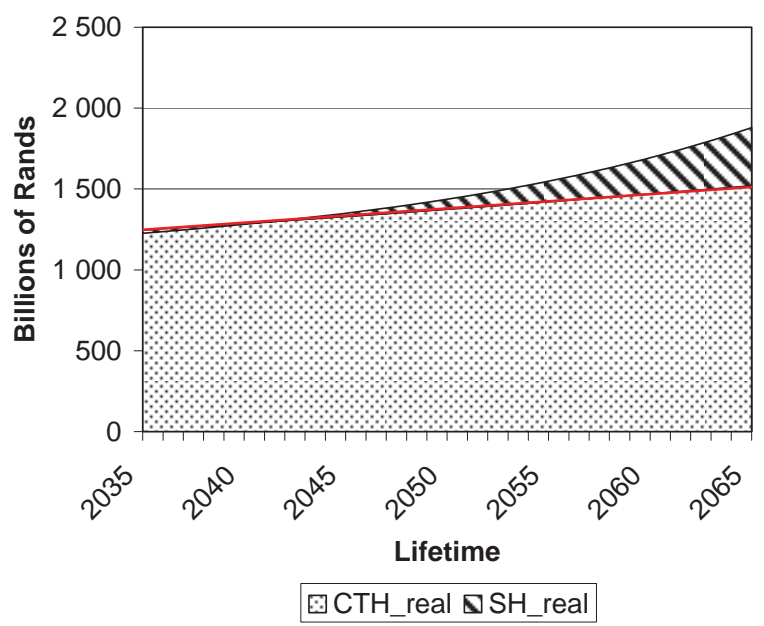

Savings-consumption plan 2050, SIM-LoSH

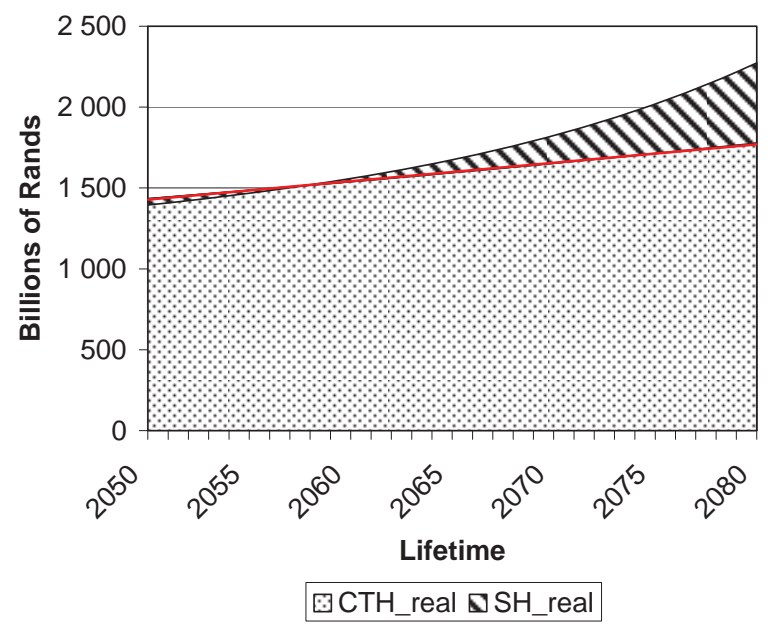

respectively. As ti me goes by, successive plans call for lower and lower savings in the current period (indeed, negative fro m 2017 onwards), with sharp er planned increases in the future. Overall, good intentions never materialize, because only the first period of each successive plan is actually applied, and the model crashes in 2053 as household wealth threatens to turn negative.

Figure 8 displays household savings and consum ption plans in the Sim -HiSH scenario, as they stand in 2020 and 2050. It can be s een that the situation is re versed compared to the LoSH situation. Households

Figure 8

Savings-consumption plan 2020, SIM-HiSH

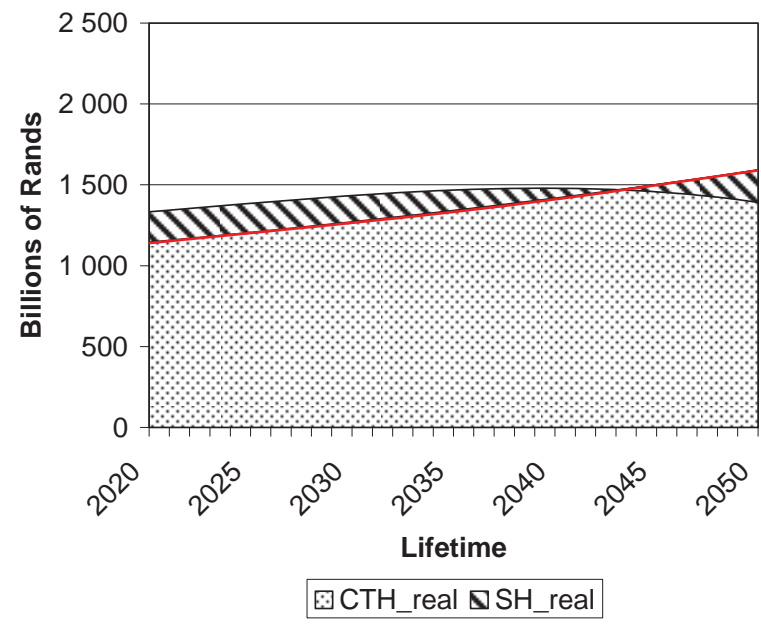

Savings-consumption plan 2050, SIM-HiSH

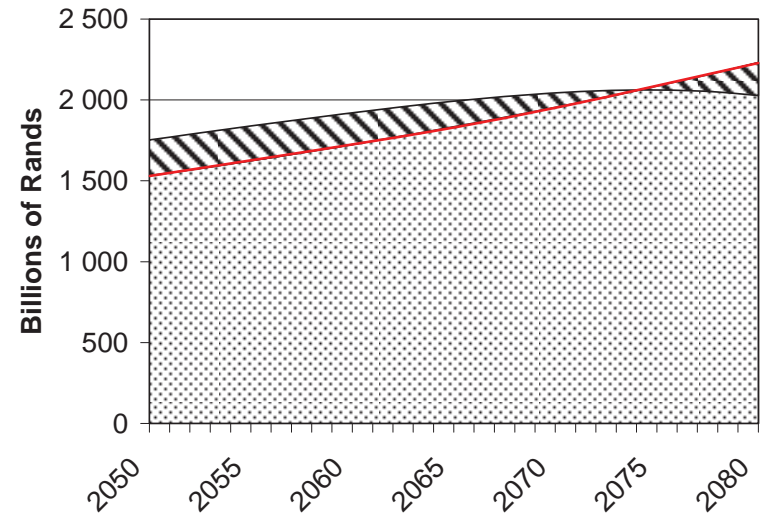

Lifetime

国CTH_real $\mathbf{\Sigma} S H \_r e a l$ 
expect their income to peak at some point in the future, and then to decline. This foreseen evolution is the result of a slow anticipated increase in non-investm ent income (YDHX), combined with an evolution of capital income that reflects a planned wealth accu mulation-decumulation cycle (see comments on Figure 9 below). H ouseholds plan to save and accum ulate wealth for some tim e before dissaving, so that consumption expenditures can keep ri sing to the end of their plan ning horizon. As in the pr evious case, this pattern repeats itself in every period, and household wealth never ceases to accumulate.

Figure 9 det ails how, in the SIM-HiSH scenario, households' behavior in 2050 is consistent with expectations and plans, including the transversality condition. Planned savings are positive nearly to the end of the planning tim e span, but from 2064 onwards (less than midway to the planning horizon), it is foreseen that the previous period's savings (Gro ss t-1 invest ments) will be insufficient to replace depreciated capital in the household's wealth, which will henceforth decline to attain its terminal value in year 2081, as imposed by the transversality condition. The same situation repeats itself in every period of the simulation.

\section{Figure 9 \\ Expected evolution of wealth 2050, SIM-HiSH}

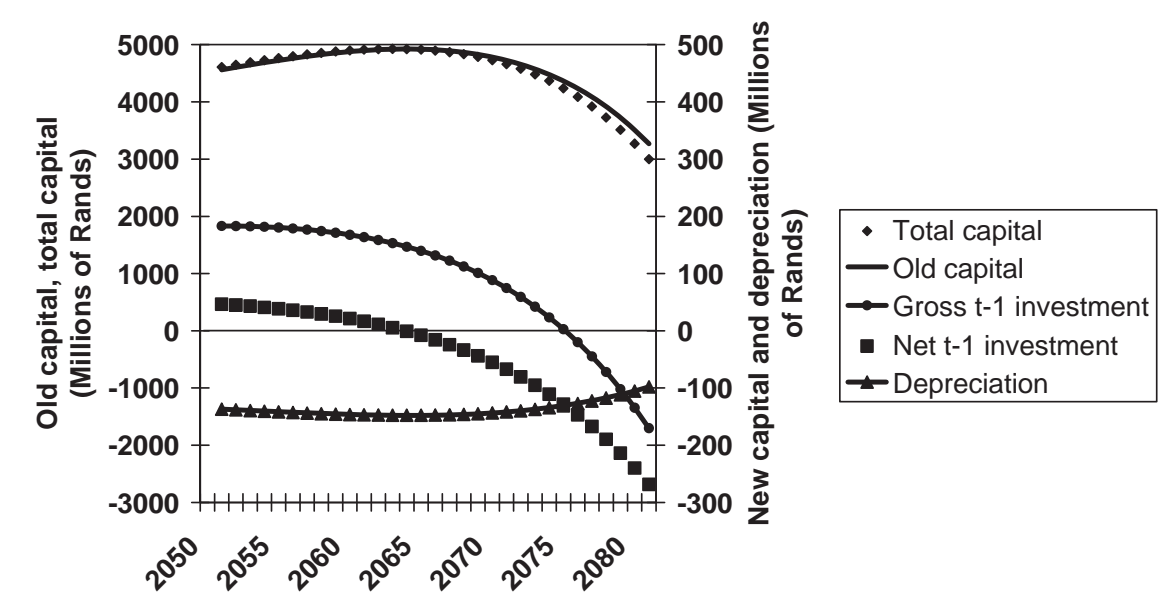

Similar consistency is observed in the LoSH case, although the picture is a little m urky. For the sake of completeness, Figure 10 details how, for exam ple, in the SIM- LoSH scenario, household behavior in 2050 is consistent with expectations and plans, including the transversality condition. 


\section{Figure 10 \\ Expected evolution of wealth \\ 2050, SIM-LoSH}

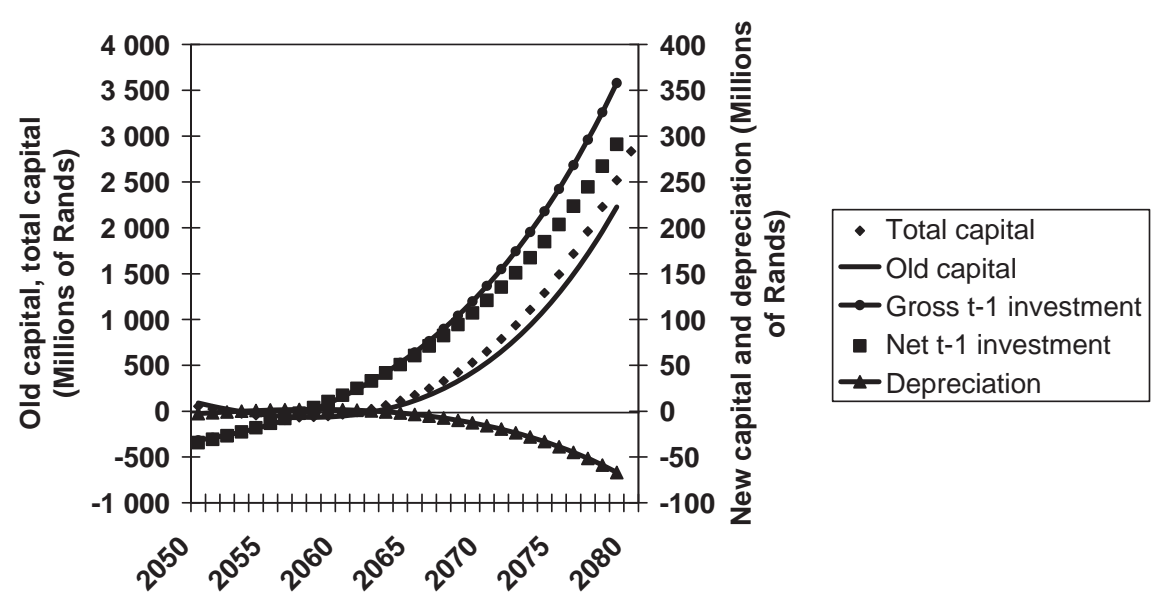

To summarize, household wealth drifts away from its target, even though the household consumption and savings decisions in each y ear, if their expectations for subsequent periods were fulfilled, would lead to an amount of wealth at the end of their thirty-year planning time span that would be equal to the targeted amount (in other words, the intertemporal optimization solution has been verified to be correct).

\subsubsection{Simulation 2: confiscation of $20 \%$ of household wealth}

This simulation is an arti fice to see what the $\mathrm{m}$ odel predicts about household reaction to a sudden reduction in their wealth, while their end-of-life cons traint (transversality condition) remains unchanged. At the beginning of 2006 (y ear 2 of the sim ulation run), $20 \%$ of househol d ownership of capital is transfered to the government. This is achieved by an exogenous arbitrary $20 \%$ reduction in the household capital ownership share variables $\lambda_{h, k, t}^{R K}$, accompanied by a corresponding incre ase in government ownership shares. Thus, household wealth shrinks instantly by $20 \%$, and so do household entitlem ents to capital income. Consequently, as households enter year 2006, they hold $20 \%$ less wealth in the simulation scenarios as in the BAU scenarios. We expected hous eholds to raise their savings rate in order to restore their level of wealth, and be able to attain their unchanged terminal wealth target.

Figure 11 shows that, contrary to expectations, the household sa vings rate is virtually unaffected by the wealth shock. 
Figure 11

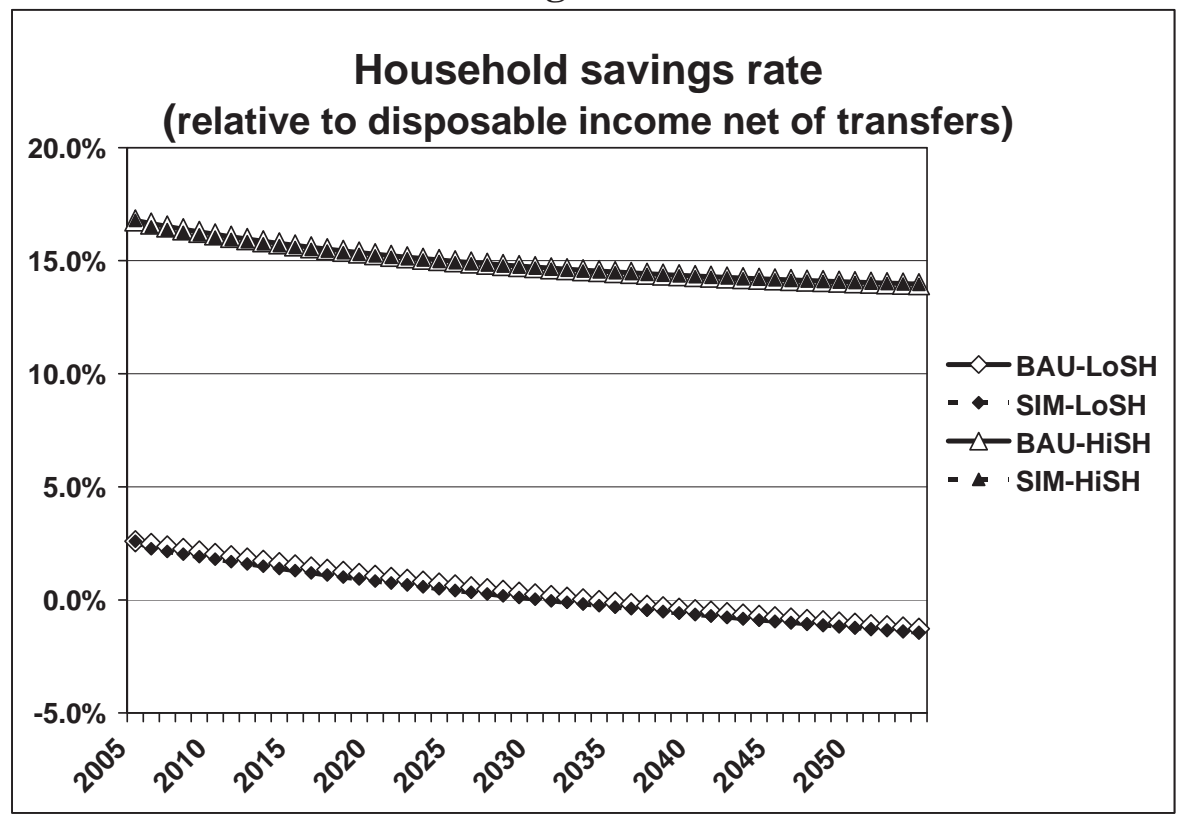

Of course, the shock does have some ef fect on real household disposable income, because of the loss of capital income (Figure 12).

Figure 12

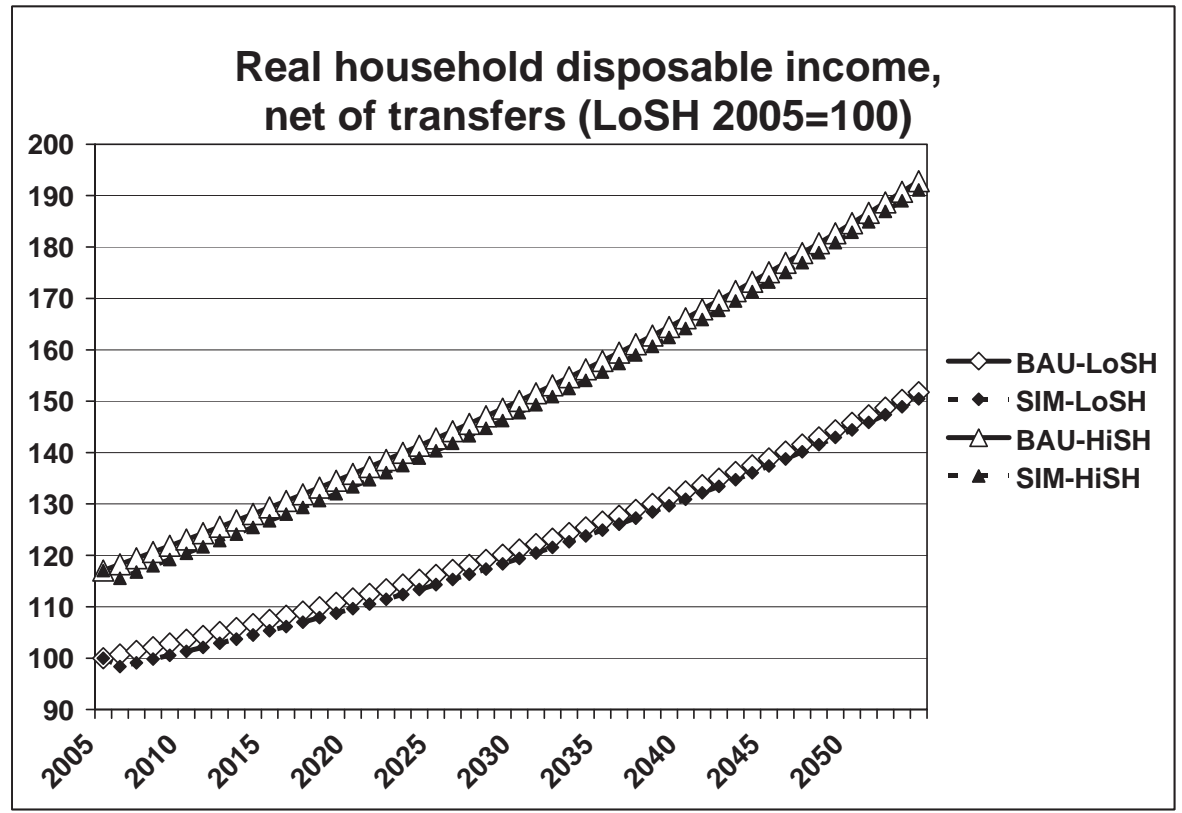

As a result, real domestic private savings are somewhat dampened (Figure 13). 
Figure 13

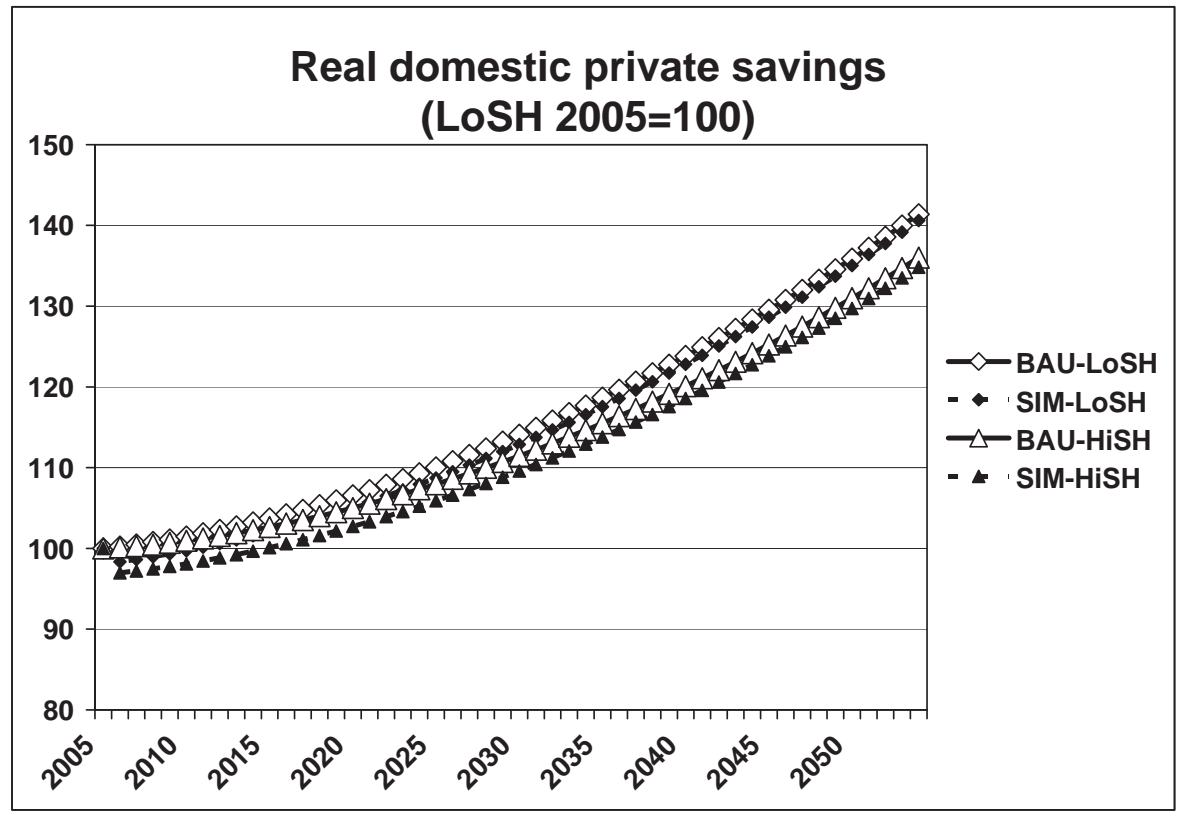

But this has little effect on household consum ption, GDP and growth (through capital accumulation), and that effect fades away as time goes by (Figures 14 and 15).

Figure 14

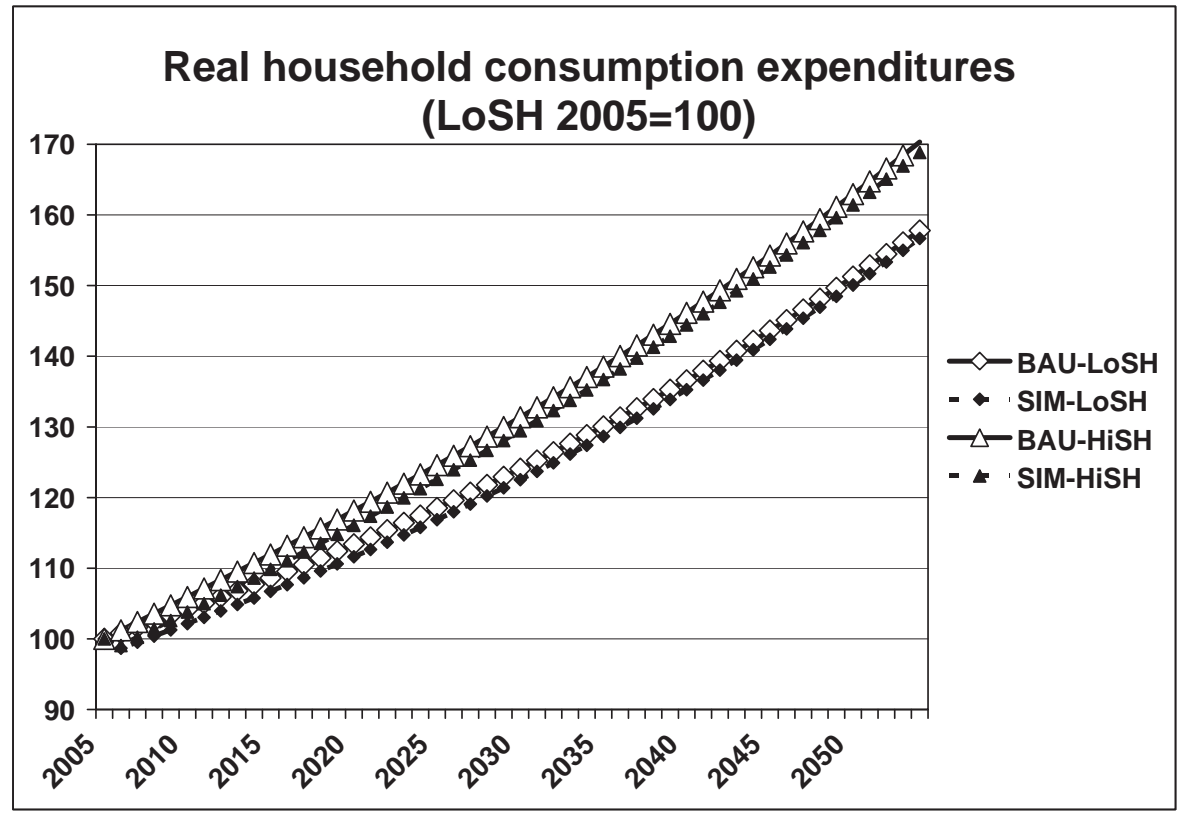


Figure 15

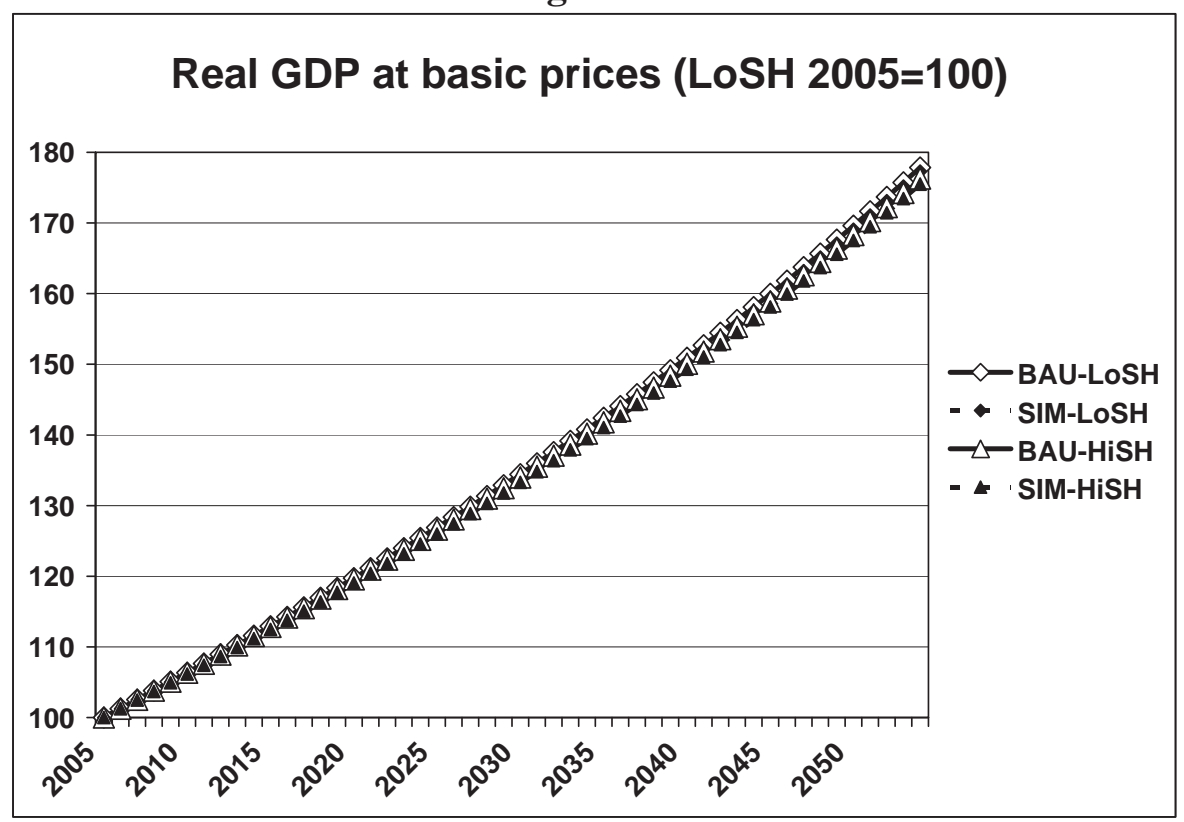

Why is the effect so weak? The explanation is found by examining the household consumption equation M 128, which is derived from intertemporal optimization.

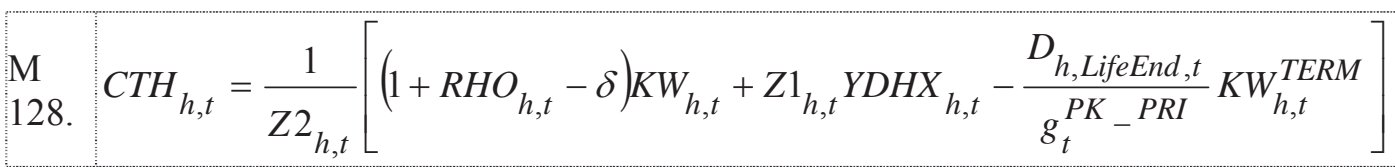

Table 2 below shows the weight of each of the th ree components between square brackets in equatio $n$ M 128, in the initial year 2005, and in 2006, after the shock in the SIM scenario, for both variants of the SAM.

Table 2 - Weights of the components of household consumption

\begin{tabular}{r|c|c|c} 
& $\left(1+R H O_{h, t}-\delta\right) K W_{h, t}$ & $Z 1_{h, t} Y D H X_{h, t}$ & $-\frac{D_{h, \text { LifeEnd }, t}}{g_{t}^{\text {PK }} \text { PRI }} W_{h, t}^{T E R M}$ \\
\hline LoSH & & & \\
\hline BAU/SIM 2005 & $12.8 \%$ & $89.4 \%$ & $-2.2 \%$ \\
BAU 2006 & $12.5 \%$ & $92.0 \%$ & $-2.2 \%$ \\
SIM 2006 & $10.2 \%$ & $89.5 \%$ & $-2.0 \%$ \\
\hline BAUSH SIM 2005 & $12.5 \%$ & $88.7 \%$ & $-2.0 \%$ \\
BAU 2006 & $13.3 \%$ & $91.2 \%$ & $-2.0 \%$
\end{tabular}

The second of the three co mponents between squ are brackets is the present value of non-investment income. It represents around $90 \%$ of the total. The s hock on household wealth affects only the first term, which initially represents about $13 \%$ of the total. The tail cannot wag the dog... 
The impact of the shock on wealth is dam pened for another, $\mathrm{m}$ ore idiosyncratic, reason. The way the shock is specified, the wealth taken away from households is transferred to government. Consequentl y, government income from capital increases. With fixed governm ent savings, there results an increase in current expenditures whi ch stimulates labor dem and, pushes the wage rat e upward, and increases household labor income, partly compensating for the loss of capital income.

\subsubsection{Simulation 3: 2\%/10\% surtax on household capital income}

In this simulation, equation M 135 is modified to add a surtax on income from capital.

$$
\text { 136. } R H O_{h, t}=\left(1-t t d h 1_{h, t}-t t d h k_{h, t}\right) R R K_{h, t}
$$

where

$$
t t d h k_{h, t}: \text { Rate of surtax on capital income of type } h \text { households }
$$

Equations M 111 and M 035 are modified accordingly. The surtax is 2\% in the LoSH variant, and 10\% in the HiSH variant. The modest $2 \%$ rate was chosen be cause a heft ier rate made the $m$ odel crash before 2054. This happened because, in the LoSH case, negative savings set on early in the simulation, and wealth threatened to turn negative.

The surtax on capital income has a noticeable effect on the savings rate, as shown in Figure 16, compared to Figure 11.

Figure 16

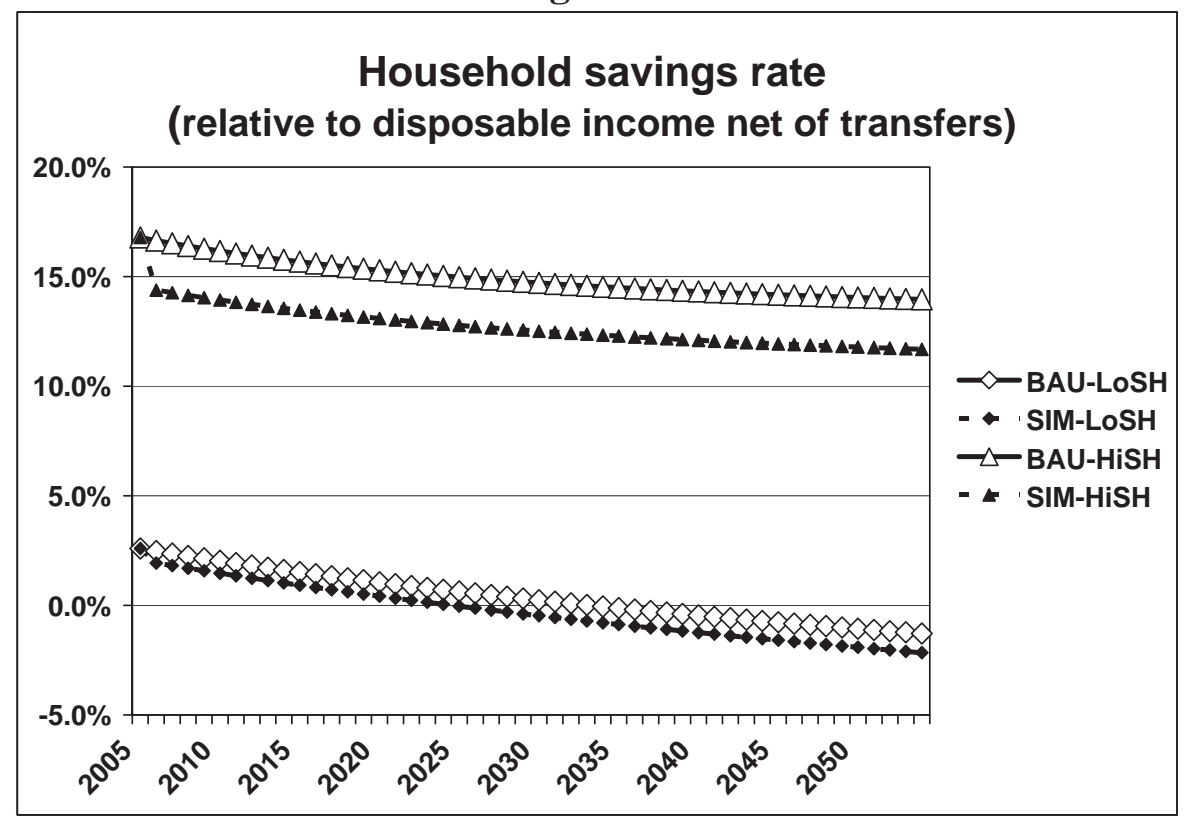


The reduction in the savings rate is reflected in the amount of domestic savings, as displayed in Figure 17. The impact is weaker in the LoSH case, becau se household savings represent only a small share of domestic savings (13.2\% in 2005), whereas they are $100 \%$ of domestic savings in the HiSH case (by construction; see 3.1 above). The contrast with simulation 2 (Figure 13) is striking.

Figure 17

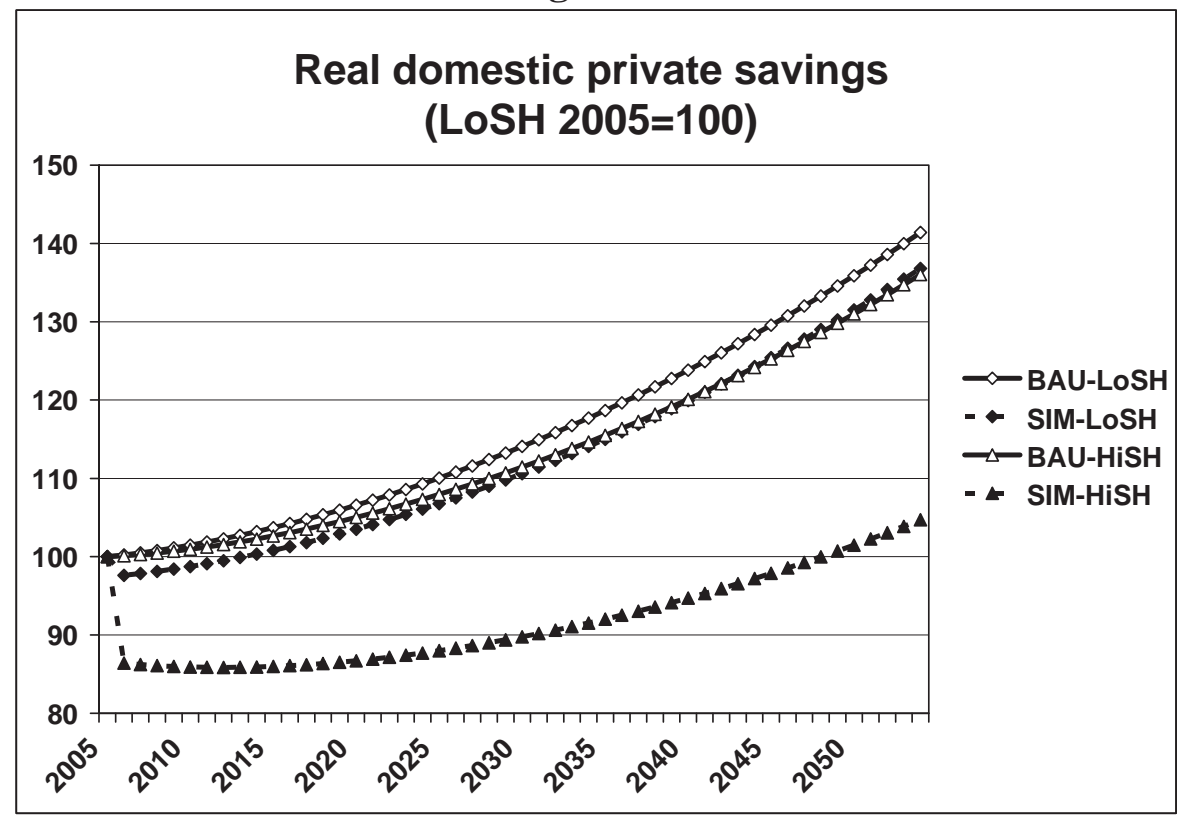

Lower savings mean less investment and slower capital accumulation. In the long run, this im plies less growth and a lower real GDP, especially in the HiSH case, as shown in Figure 18.

Figure 18

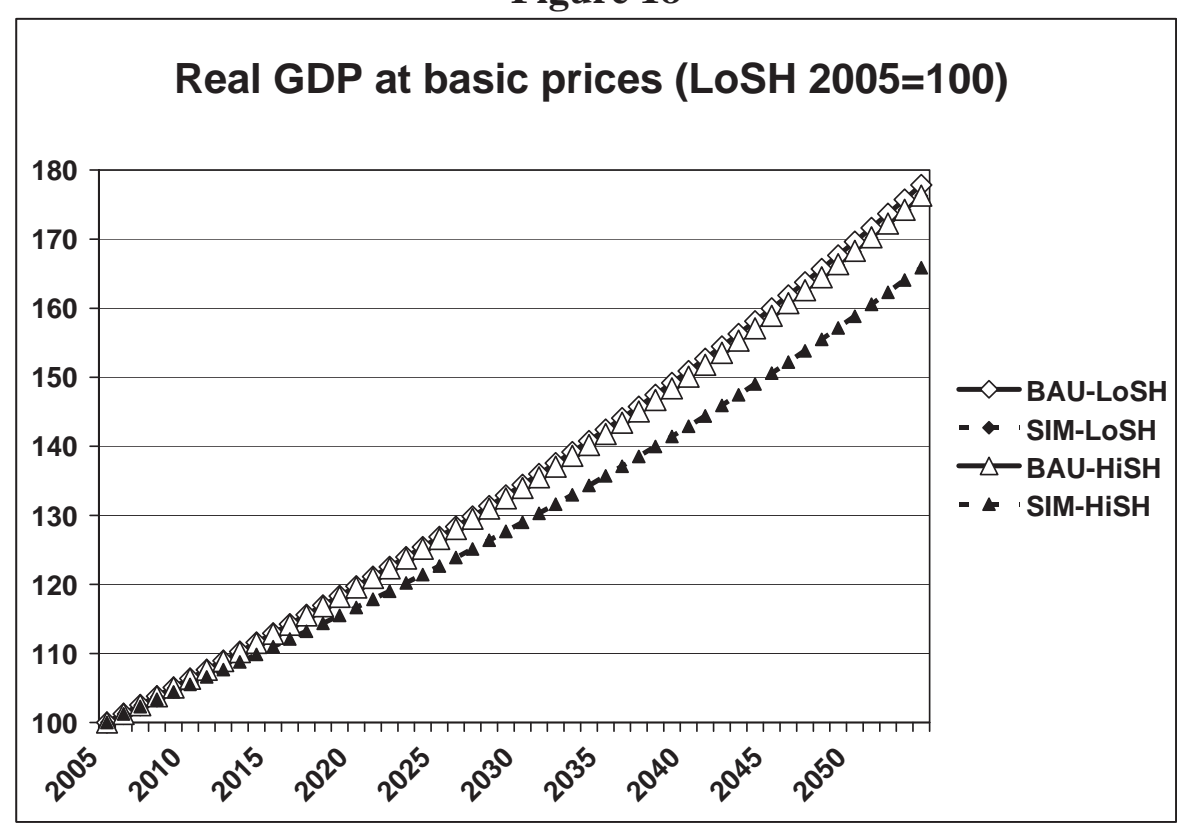




\subsubsection{Summary of simulation results}

The first si mulation, a perm anent $50 \%$ drop in the international price of minerals, showed that the behavior predicted by "truncated rational expectations" is quite radically different from the one predicted by full rational expectations and per fect foresight. Indeed, in the savings-consum ption plan that housesholds make every year, the future never $m$ aterializes: household wealth keeps drifting away from its terminal constraint value (trans versality condition), and that happens in spite of the fact that, if household expectations for subsequent periods were fulfilled, every year's plan would lead, thirty years down the road, to an amount of terminal wealth equal to the target.

The second simulation, a shock on the stock of wealth owned by households, has virtually no effect on household savings behavior. Our diagnostic is that the weight of wealth in con sumption equation M 128 is insufficient for exogenous variations in wealth to have a stro ng impact on the consu mption-savings balance.

The third simulation consisted in a (fiscal) shock on the rate of ret urn to wealth. The results highli ghted the role of the return rate as an incentive to save.

\subsection{Alternative models}

The same set of simulations were run with two other models based on the same South Africa SAMs.

\subsubsection{Static expectations}

In PEP-TRE, households apply intertemporal optimization in every period, based upon near-perfect foresight of the following period and extrapolation i nto the future. With static expectations, households expect the values of the relevant variables to remain at their current levels indefinitely . In our staticexpectations model, households apply intertemporal optimization in every period based upon such static expectations. There is no need for recalibration as in PEP-TRE, and the GAMS coding of the model may be a lot simpler. Technically, however, we used the PEP-TRE code, skipping r ecalibration and fixing all growth factors exogenously at 1 (no growth).

\section{Simulation 1: permanent 50\% drop in the international price of minerals}

We shall spare the reader a detailed examination of the results with the static-expectations model. The key difference is that the savings rate with static expect ations is higher, both in the LoSH and in the HiSH case, except for the first 20 years (2006-2021) of the SIM-LoSH scenario, as displayed in Figure 19. 
Figure 19a

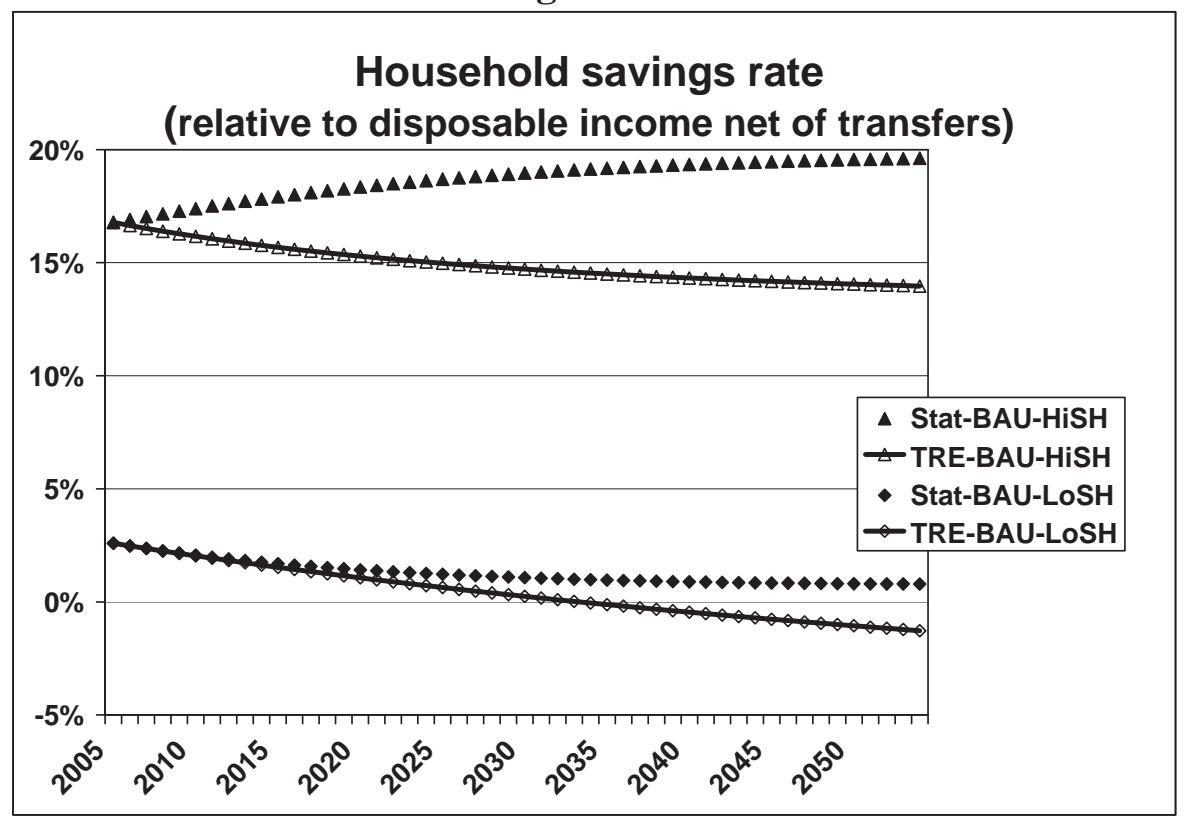

Figure 19b

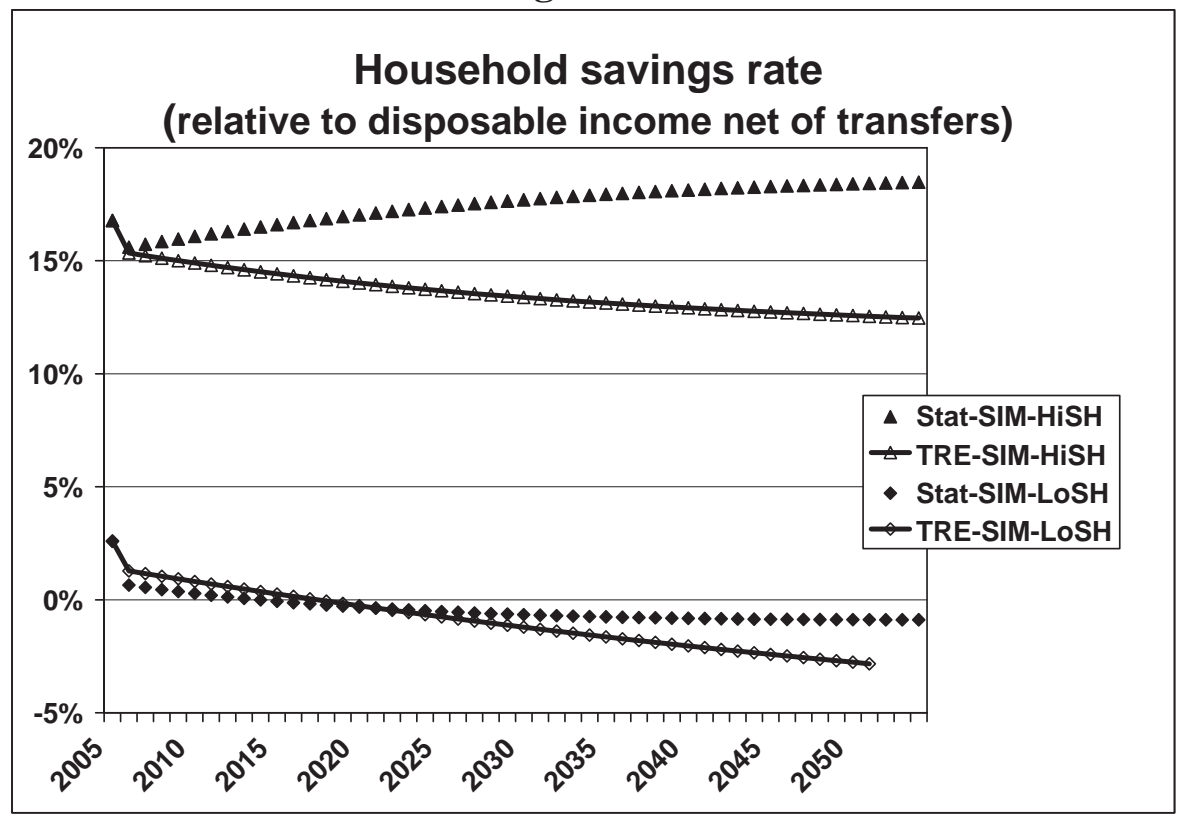

It would appear that this is largely explained by the combined effects of the growth factors in PEP-TRE. In particular, the growth $\mathrm{f}$ actors influence $Z 1_{h, t}$ and $Z 2_{h, t}$ directly, and indirectly through $D_{h, \text { Lifetime,t }}$ (equations M 125-127). We observe that the $Z 1_{h, t} / Z 2_{h, t}$ ratio is generally higher in the PEP-TRE model compared to the static-expectations model, which, from equation M 128, implies that households allocate a larger share of their non-investm ent income to consum ption. Given the preponderance of non- 
investment income in determining the level of consu mption expenditures (see Table 2), it follows that a higher $Z 1_{h, t} / Z 2_{h, t}$ ratio is likely to result in a lower savings rate.

Other differences between the static-expectations model and PEP-TRE follow. Higher savings rates result in larger domestic savings, more investment and capital accumulation, and accelerated growth.

\section{Simulations 2 and 3}

Just as with the PEP-TRE model, the $20 \%$ wealth meltdown has practically no effect. And the $2 \% / 10 \%$ tax on capital income has a si milar disincentive effect on savings, except that, as Simulation 1 leads us to expect, savings tend to be higher with the static-expectations model, especially in the HiSH variant.

\subsubsection{Fixed savings rate}

The same set of sim ulations were run for com parison purposes with a fixed-savings rate $m$ odel. The model used is a modified version of PEP-1-t, where investment income shares evolve according to agents' savings and contribution to investment. In addition, the interest rate was redefined following equation M 129 above, and the scale parameter $\phi_{t}$ is treated as an endogenous vari able, as explained in 2.2 and in the appendix.

\section{Simulation 1: permanent 50\% drop in the international price of minerals}

The first obvious thing to observe is that the savings rate is greater in the fixed-savings rate model than in PEP-TRE (see Figure 5), since they fall in the latter ; compared to the static-expectations $m$ odel, the savings rate is greater in the LoSH case, and less in the HiSH case (see Figure 19). It follows that capital accumulation and growth are higher with fixed household savings rates than in the two other models, except in the HiSH case, where they are lower than in the static-expectations model. The same is true of household wealth.

With fixed savings rates, the allocation of nom inal disposable income after transfers between consumption and savings is constant. However, in sim ulations, consumer prices fall $\mathrm{m}$ ore than the price of the capital good relative to the BAU, so that in real term s, consumption expenditures contract less than savings.

\section{Simulations 2 and 3}

Just as with the PEP-TRE and static-expectations models, the $20 \%$ wealth meltdown has practically no effect. Finally, given the fixit y of savings rates, the $2 \% / 10 \%$ tax on capital inco me has no disincentive effect on savings, in sharp contrast with the two other models. 


\section{Conclusion: What remains to be done}

Much remains to be explored and understood in the se results. In particular, why do savings rates fall continuously in PEP-TRE, both in the high- and in the low savings rate situati ons? A conjecture is that this is related to the fact that prices tend to fall slowly in all s cenarios, but the fall is less and less pronounced. Thus household price expectations, based on t he current period and the next, overestimate the long term trend in price decline, and this leads them to under-save.

More generally, other simulations should be run, to $m$ ore fully assess the responsiveness of household savings rates to changes in the rate of return on as sets and to shocks on the stock of wealth. And the model's sensitivity to the arbitrary va lues of free param eters should be explored (Planning horizon, intertemporal elasticity of substitution, psy chological discount rate, uniform rental rate of capital, specification of the terminal wealth constraint...).

Most importantly, the model presented here is inco mplete in that, in its present state, it could not accommodate a SAM wher e some agents have negative savings. That is the reason why the 2005 South African SAM was chosen: all agents have positive s avings. Indeed, we have assu med that ownership of the new capital created fro $\mathrm{m}$ investment is distributed in proportion to each agent' s savings. But if so me agents have negative savings, they draw from the pool of savings to equilibrate their budget. And so part of the savings of other age nts is diverted from investment in productive capital. To correctly account for wealth accumulation, it is necessary to introduce (at least) another asset.

For example, if a country runs a current account surplus, then foreign savings ar e negative and there is an implicit capital-and-financial account flow of funds out of domestic savings to the RoW. It follows that domestic agents accumulate wealth partly in the form of investment abroad (portfolio investment or FDI). Similarly, if there is a governm ent deficit, other agents accu mulate wealth partly in the form of government debt securiti es (bonds). These other forms of wealth need to be taken in to account if intertemporal optimization is to be consistent.

That's how Pandora's Box yawns wide open... B ecause accounting for financial assets poses several challenges. The first is a data challenge: we would need to have or construct data relating to stocks and flows of financial assets, and to flows of incom e paid and received in relation to financial asset $\mathrm{s}$. The second is a modelling challenge: if savings are to be explicitly allocated to various assets, then we need a portfolio allocation mechanism and a pricing mechanism. Similar challenges arise in the context of world models which take into account capital-and-financial account flows and net international investm ent positions (Lemelin et al. 2013), and perhaps so me of the solutions develope d in that context can be transposed to PEP-TRE. 


\section{References}

BABIKER, M., A. GURGEL, S. PALTSEV and J. REILLY (2009) « Forward-looking versus recursivedynamic modeling in climate policy analysis: A comparison », Economic Modelling, 26: 1341-1354.

DAVIES, R. and J. THURLOW (2011), A 2005 Social Accounting Matrix for South Africa, International Food Policy research Institute (IFPRI), Washington D.C.

De GRAUWE, P. (2012) « Booms and busts in economic activity: A behavioral explanation », Journal of Economic Behavior \& Organzation, 83: 484-501.

De GRAUWE, P. (2010) «The scientific foundation of dynamic stochastic general equilibrium (DSGE) models », Public Choice, 144: 413-443.

DECALUWÉ, Bernard, André LEMELIN, Véronique ROBICHAUD et Hélène MAISONNAVE (2013), PEP-1-t. The PEP standard single-country, recursive dynamic CGE model (Version 2.1), Partnership for Economic Policy (PEP) Research Network, Université Laval, Québec.

http://www.pep-net.org/programs/mpia/pep-standard-cge-models/

EVANS, G.W. and S. HONKAPOHJA (2001), « Economics of Expectations », in N.J. Smelser, J. Wright and P.B. Baltes, International Encyclopedia of the Social and Behavioral Sciences, Elsevier http://dx.doi.org/10.1016/B0-08-043076-7/02245-2

HOWE, H. (1975), « Development of the extended linear expenditure s ystem from simple saving assumptions », European Economic Review, vol. 6, p. 305-310.

LEMELIN, André, Véronique ROBICHAUD et Bernard DECALUWÉ (2013) « Endogenous current account balances in a world CGE m odel with international financial assets », Economic Modelling, 32 (May), 146-160.

http://dx.doi.org/10.1016/j.econmod.2013.01.046

LEMELIN, André (2013) Household savings under intertemporal optimization with a depreciating asset and truncated rational expectations in a recursive-dynamic CGE model, Unpublished report prepared for the International Food Production Research Institute (IFPRI), Washington D.C.

LEMELIN, André (2012) Household savings under intertemporal optimization with boundedly rational expectations in a recursive-dynamic CGE model: A proposal, Unpublished re port prepared for th e International Food Production Research Institute (IFPRI), Washington D.C.

LEMELIN, André et Bernard DECALUWÉ (2007) Questions de modélisation : l'investissement par destination, l'épargne et la dette publique dans un modèle d'équilibre général calculable dynamique séquentiel. Une revue des écrits - Issues in Recursive Dynamic CGE Modeling: Investment by destination, Savings, and Public Debt - A Survey, CIRPÉE et INRS-UCS, 128 pages.

http://www.pep-net.org/fileadmin/medias/pdf/RevLitt_MEGC_FR.pdf http://www.pep-net.org/fileadmin/medias/pdf/RevLitt_MEGC_EN.pdf

LLUCH, C. (1973), « The extended linear expenditure system », European Economic Review, vol. 4, p. 21-32.

LÖFGREN, H., R.L. HARRIS and S. ROBINSON (2002), A Standard Computable General Equilibrium (CGE) Model in GAMS, International Food Policy Research Institute (IFPRI), Washington, D.C. http://www.ifpri.org/sites/default/files/publications/mc5.pdf

SIMON, Herbert A. (1982) Models of bounded rationality, Vol. 1-3, MIT Press.

SIMON, Herbert A. (1978) "Rationality as process and as product of thought", American Economic Review, 68(2): 1-16. 
WÄLDE, Klaus (2011), Applied intertemporal optimization, Edition 1.1, Gutenberg Research College, University of Mainz, Germany.

http://www.waelde.com/pdf/AIO.pdf 


\section{Appendix : Aggregation}

\begin{tabular}{|c|c|c|c|c|}
\hline \multicolumn{5}{|c|}{ Activities and Commodities } \\
\hline & & Original classification & & Aggregation \\
\hline & Code & Description & Code & Description \\
\hline 1 & agri & Agriculture & Agr-for-fsh & Agriculture, forestry \& fisheries \\
\hline 2 & fore & Forestry & Agr-for-fsh & Agriculture, forestry \& fisheries \\
\hline 3 & fish & Fisheries & Agr-for-fsh & Agriculture, forestry \& fisheries \\
\hline 4 & coal & Coal mining & Mining & Mining \\
\hline 5 & omin & Other mining & Mining & Mining \\
\hline 6 & meat & Meat & Food & Food \\
\hline 7 & pfsh & Fish & Food & Food \\
\hline 8 & fveg & Fruit \& vegetables & Food & Food \\
\hline 9 & oils & Oils \& fats & Food & Food \\
\hline 10 & dair & Dairy & Food & Food \\
\hline 11 & mill & Grain milling & Food & Food \\
\hline 12 & star & Starches & Food & Food \\
\hline 13 & feed & Animal feeds & Food & Food \\
\hline 14 & bake & Bakery & Food & Food \\
\hline 15 & sugr & Sugar & Food & Food \\
\hline 16 & conf & Confectionary products & Food & Food \\
\hline 17 & past & Pastas & Food & Food \\
\hline 18 & food & Other foods & Food & Food \\
\hline 19 & btob & Beverages \& tobacco & Bev\&tob & Beverages \& tobacco \\
\hline 20 & fabr & Weaving \& finishing of fabrics & Tex\&cloth & Textiles \& clothing \\
\hline 21 & made & Made-up textiles & Tex\&cloth & Textiles \& clothing \\
\hline 22 & carp & Carpets, rugs \& mats & Tex\&cloth & Textiles \& clothing \\
\hline 23 & text & Other textiles & Tex\&cloth & Textiles \& clothing \\
\hline 24 & knit & Knitting \& crocheted fabrics & Tex\&cloth & Textiles \& clothing \\
\hline 25 & wear & Wearing apparel & Tex\&cloth & Textiles \& clothing \\
\hline 26 & leat & Leather products & Tex\&cloth & Textiles \& clothing \\
\hline 27 & foot & Footwear & Tex\&cloth & Textiles \& clothing \\
\hline 28 & wood & Wood products & Wood\&pap & Wood \& paper \\
\hline 29 & papr & Paper products & Wood\&pap & Wood \& paper \\
\hline 30 & prnt & Printing \& publishing & Wood\&pap & Wood \& paper \\
\hline 31 & petr & Petroleum products & Petro & Petroleum products \\
\hline 32 & bchm & Basic chemicals & Chemicals & Chemicals \\
\hline 33 & fert & Fertilizers \& pesticides & Chemicals & Chemicals \\
\hline 34 & pain & Paints \& related products & Chemicals & Chemicals \\
\hline 35 & phar & Pharmaceuticals & Chemicals & Chemicals \\
\hline 36 & soap & Soap \& related products & Chemicals & Chemicals \\
\hline 37 & ochm & Other chemicals & Chemicals & Chemicals \\
\hline 38 & tyre & Rubber tyres & Chemicals & Chemicals \\
\hline 39 & rubb & Other rubber products & Chemicals & Chemicals \\
\hline 40 & plas & Plastics & Chemicals & Chemicals \\
\hline 41 & glas & Glass products & Non-metall & Non-metallic minerals \\
\hline 42 & cere & Ceramicware & Non-metall & Non-metallic minerals \\
\hline 43 & ceme & Cement & Non-metall & Non-metallic minerals \\
\hline
\end{tabular}


Activities and Commodities

\begin{tabular}{|c|c|c|c|c|}
\hline & & Original classification & & Aggregation \\
\hline & Code & Description & Code & Description \\
\hline$\overline{44}$ & nmet & Other non-metallic minerals & Non-metall & Non-metallic minerals \\
\hline 45 & iron & Basic iron \& steel & Metal & Metal products \\
\hline 46 & nfer & Non-ferrous metal & Metal & Metal products \\
\hline 47 & metp & Metal products & Metal & Metal products \\
\hline 48 & engn & Engines \& turbines & Mechanic & Mechanical equipment \\
\hline 49 & pump & Pumps, compressors \& valves & Mechanic & Mechanical equipment \\
\hline 50 & bear & Bearings \& gears & Mechanic & Mechanical equipment \\
\hline 51 & lift & Lifting equipment & Mechanic & Mechanical equipment \\
\hline 52 & gmch & General purpose machinery & Mechanic & Mechanical equipment \\
\hline 53 & smch & Special purpose machinery & Mechanic & Mechanical equipment \\
\hline 54 & appl & Domestic appliances & Elec\&Eltron & Electric \& electronic \\
\hline 55 & omch & Office machinery & Elec\&Eltron & Electric \& electronic \\
\hline 56 & emch & Electrical machinery & Elec\&Eltron & Electric \& electronic \\
\hline 57 & rtel & Radio \& television equipment & Elec\&Eltron & Electric \& electronic \\
\hline 58 & mequ & Medical equipment & Elec\&Eltron & Electric \& electronic \\
\hline 59 & vehe & Vehicles \& parts & Trnsp_eqp & Transport equipment \\
\hline 60 & ship & Ships \& boats & Trnsp_eqp & Transport equipment \\
\hline 61 & rail & Railways \& trams & Trnsp_eqp & Transport equipment \\
\hline 62 & airc & Aircraft & Trnsp eqp & Transport equipment \\
\hline 63 & otrn & Other transport equipment & Trnsp_eqp & Transport equipment \\
\hline 64 & furn & Furniture & Oth manu & Other manufacturing \\
\hline 65 & jewe & Jewellery & Oth_manu & Other manufacturing \\
\hline 66 & oman & Other manufacturing & Oth_manu & Other manufacturing \\
\hline 67 & rcyc & Recycling \& waste & Oth_manu & Other manufacturing \\
\hline 68 & elec & Electricity \& gas distribution & E\&Gdistrib & Electricity \& gas distribution \\
\hline 69 & watr & Water distribution & WatDistrib & Water distribution \\
\hline 70 & cons & Construction & Construc & Construction \\
\hline 71 & $\operatorname{trad}$ & Wholesale \& retail trade & Trade & Wholesale \& retail trade \\
\hline 72 & hotl & Hotels \& catering & Hotels & Hotels \& catering \\
\hline 73 & $\operatorname{tran}$ & Transport & Transport & Transport \\
\hline 74 & comm & Post \& communications & Post\&comm & Post \& communications \\
\hline 75 & fsrv & Financial services & Fin_serv & Financial services \\
\hline 76 & insu & Insurance \& pensions & Ins\&pens & Insurance \& pensions \\
\hline 77 & real & Real estate activities & Real_est & Real estate activities \\
\hline 78 & rdev & Research \& development & Oth_bus & Other business services \\
\hline 79 & legl & Legal $\&$ accounting activities & Oth_bus & Other business services \\
\hline 80 & rent & Rental services & Oth_bus & Other business services \\
\hline 81 & busi & Other business activities & Oth_bus & Other business services \\
\hline 82 & govn & Public administration & Pub_adm & Public administration \\
\hline 83 & educ & Education & Education & Education \\
\hline 84 & heal & Health & Health & Health \\
\hline 85 & osrv & Other services & Oth_serv & Other services \\
\hline
\end{tabular}




\section{Appendix : The endogenous investment scale variable as a rationing device}

In PEP-1-t, the investment equation is

108. IND $D_{k, b u s, t}=\phi_{k, b u s}\left[\frac{R_{k, b u s, t}}{U_{k, b u s, t}}\right]^{\sigma_{k, b u s}^{I N V}} K D_{k, b u s, t}$

with

109. $U_{k, b u s, t}=P K_{t}^{P R I}\left(\delta_{k, b u s}+I R_{t}\right)$ and $U_{k, p u b, t}=P K_{t}^{P U B}\left(\delta_{k, p u b}+I R_{t}\right)$

In practice however, the PEP-1-t calibration procedure results in uniform values for $\phi_{k, j}$, so we might as well write PEP-1-t equation 108 as

$$
\text { iii . } \quad I N D_{k, b u s, t}=\phi^{*}\left[\frac{R_{k, b u s, t}}{U_{k, b u s, t}}\right]^{\sigma_{k, b u s}^{I N V}} K D_{k, b u s, t}
$$

The interest rate $I R_{t}$ appears nowhere else in the PEP -1-t model, and it takes whatever value it $\mathrm{m}$ ust for the equilibrium constraint

105. $I T_{t}^{P R I}=P K_{t}^{P R I} \sum_{k, \text { bus }} I N D_{k, b u s, t}$

to be satisfied.

In PEP-TRE, however, the forward-looking interest rate is tied to the expected rate of return on capital :

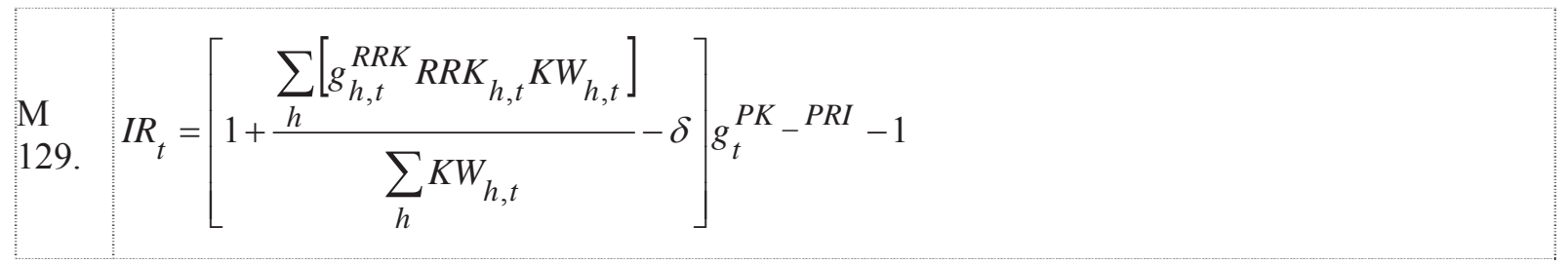

To clarify the relationship between the two formulations, let us rename the PEP-1-t « wild card » interest rate as $I R_{t}^{*}$, and the corresponding user cost of capital as

$$
\text { iii . } \quad U_{k, b u s, t}^{*}=P K_{t}^{P R I}\left(\delta_{k, b u s}+I R_{t}^{*}\right) \text { and } U_{k, p u b, t}^{*}=P K_{t}^{P U B}\left(\delta_{k, p u b}+I R_{t}^{*}\right)
$$

It is required that 
iii . $\quad I N D_{k, b u s, t}=\phi^{*}\left[\frac{R_{k, b u s, t}}{U_{k, b u s, t}^{*}}\right]^{\sigma_{k, b u s}^{I N V}} K D_{k, b u s, t}=\phi_{t}\left[\frac{R_{k, b u s, t}}{U_{k, b u s, t}}\right]^{\sigma_{k, b u s}^{I N V}} K D_{k, b u s, t}$

It follows that the following must hold

iii . $\quad \phi^{*}\left[\frac{1}{U_{k, b u s, t}^{*}}\right]^{\sigma_{k, b u s}^{I N V}}=\phi_{t}\left[\frac{1}{U_{k, b u s, t}}\right]^{\sigma_{k, b u s}^{I N V}}$

Whence

$$
\begin{aligned}
& \text { iii . } \phi_{t}=\phi^{*}\left[\frac{U_{k, b u s, t}}{U_{k, b u s, t}^{*}}\right]^{\sigma_{k, b u s}^{I N V}} \\
& \text { iii . } \phi_{t}=\phi^{*}\left[\frac{P K_{t}^{P R I}\left(\delta_{k, b u s}+I R_{t}\right)}{P K_{t}^{P R I}\left(\delta_{k, b u s}+I R_{t}^{*}\right)}\right]^{\sigma_{k, b u s}^{I N V}} \\
& \text { iii . } \phi_{t}=\phi^{*}\left[\frac{\delta_{k, b u s}+I R_{t}}{\delta_{k, b u s}+I R_{t}^{*}}\right]^{\sigma_{k, b u s}^{I N V}}
\end{aligned}
$$

The endogenous scale variable $\phi_{t}$ is a function of the calibrated fixed scale param eter $\phi^{*}$ and of both the forward-looking interest rate and the PEP-1-t wild card rationing interest rate . An equivalent $\mathrm{m}$ odel formulation would be t o maintain fixed investm ent scale parameters in PEP-TRE as in PEP-1-t, and define two interest rates, a forwar d-looking rate of interest that guides households in their i ntertemporal optimization, and a wild card cost-of-borrowing $r$ ate of interest that rations investible funds am ong competing uses. But what, then, would be the relationship between the two? That question is hard to answer, given that the Jun g-Thorbecke-inspired investment equation is only loosely related to Tobin's $q$ theory of investment, as discussed in Part 1 of Lemelin and Decaluwé (2007, especially p. 29-30).

Finally, it could be $\mathrm{m}$ entioned somewhat crassly that the MIRAGE m odel uses an endogenous scale variable similar to $\phi_{t}$ to ration investment. 